\title{
Los hornos de reverbero andinos. Dinámicas de transferencias e innovaciones de tecnologías metalúrgicas indígenas y europeas
}

\section{Andean reverberation furnaces. The dynamics of innovation and transfer of indigenous and european metallurgical technologies}

Pablo Cruz ${ }^{1}$ https://orcid.org/0000-0002-1349-6397

Florian Téreygeol ${ }^{2}$ https://orcid.org/0000-0003-0629-2473

${ }^{1}$ UE-CISOR 25749, Consejo Nacional de Investigaciones Científicas y Técnicas -Universidad Nacional de Jujuy. Independencia 575, San Salvador de Jujuy (4600), ARGENTINA. Email: saxrapablo@gmail.com ${ }^{2}$ CNRS, UMR5060 IRAMAT-LMC, Université Paris-Saclay, CEA Saclay 91191 Gif sur Yvette Cedex, FRANCIA. Email: florian.tereygeol@cea.fr.

\section{Resumen \\ Articulando las informaciones brindadas por las fuentes documentales coloniales con datos arqueológicos y aquellos resultantes de pruebas de arqueología experimental, en este artículo nos centraremos en una determinada categoría de horno de reverbero, utilizado en el espacio surandino desde los primeros momentos de la Colonia, principalmente para la producción de plata. Testimonios de esta categoría de horno, compuesto de tres cuerpos (cámara de fuego, cámara de trabajo abovedada y chimenea), fueron identificados en distintos centros mineros-metalúrgicos estudiados en el sur de Bolivia (Potosí, Santa Isabel, Mina Santiago, Escoriani, entre otros). Contestando la caracterización generalizada de estos hornos como de tradición europea, en este trabajo proponemos que esta tecnología resultó de un desarrollo tecnológico local, mostrando algunas continuidades significativas con la metalurgia prehispánica, la cual posteriormente se difundió en Europa.}

Palabras clave: metalurgia andina, horno de reverbero, continuidades tecnológicas.

\begin{abstract}
Bringing together information from colonial-era historical sources, archaeological data, and the results of archaeological experimentation, this work addresses reverberation furnaces, a kind of metallurgical furnace used in the southern Andes from the first moments of Spanish colonial efforts to produce silver in the region. Evidence of this three-chamber oven (composed of a fire chamber, vaulted work chamber, and chimney), has been identified and studied in different mining and metallurgical contexts in the south of Bolivia (Potosí, Santa Isabel, Mina Santiago, Escoriani, among others). Here, we show the continuities between pre-Hispanic metallurgy and reverbation furnaces. We challenge the general characterization of these furnaces as a European tradition, and propose instead that they were the result of local technological developments and later spread throughout Europe.
\end{abstract}

Keywords: Andean metallurgy, reverberatory furnace, technological continuities.

Recibido: 1 noviembre 2017. Aceptado: 3 mayo 2019 
Uno de los componentes más característicos de los establecimientos metalúrgicos coloniales presentes en el espacio surandino son los hornos de reverbero, los cuales fueron empleados tanto para la reducción de menas de minerales metalíferos no ferrosos como para la refinación de compuestos metálicos, principalmente argentíferos. No obstante su notoria difusión, los hornos de reverbero surandinos fueron muy poco estudiados por la historia de las técnicas y la arqueología, siendo a priori considerados como testimonios de la aplicación en los Andes de una tecnología de origen europeo. No obstante, varios elementos nos sugieren que al menos una categoría de horno de reverbero, y la más común fuera de los grandes centros mineros, fue el resultado de dinámicas locales de desarrollo e innovación que aplicaron saberes y tecnologías indígenas que remontan a tiempos prehispánicos. Más aún, como lo veremos, es muy probable que esta tecnología, en todos los casos asociada con el mundo indígena, partiera de los Andes para difundirse masivamente en Europa durante las primeras décadas del siglo XVII. Articulando las informaciones brindadas por las fuentes documentales coloniales con datos arqueológicos y aquellos resultantes de pruebas de arqueología experimental, en esta comunicación nos centraremos en esta categoría de horno de reverbero utilizado en el espacio surandino desde los primeros momentos de la Colonia. A diferencia de las wayras restringidas al procesamiento de minerales de plata con alta ley, estos hornos de reverbero andinos posibilitaron el beneficio de minerales con composiciones más variadas. Testimonios de esta categoría de horno de reverbero, los mismos compuestos de tres cuerpos o segmentos (cámara de fuego, cámara de trabajo abovedada y chimenea) fueron identificados en distintos centros mineros estudiados en el sur de Bolivia (Potosí, Santa Isabel, Mina Santiago, Escoriani, entre otros), cuya cronología se extiende desde mediados del siglo XVI hasta el siglo XVIII, así como también en distintos establecimientos de la puna de Jujuy (Angiorama y Becerra, 2010; Becerra et al., 2014) (Figura 1).

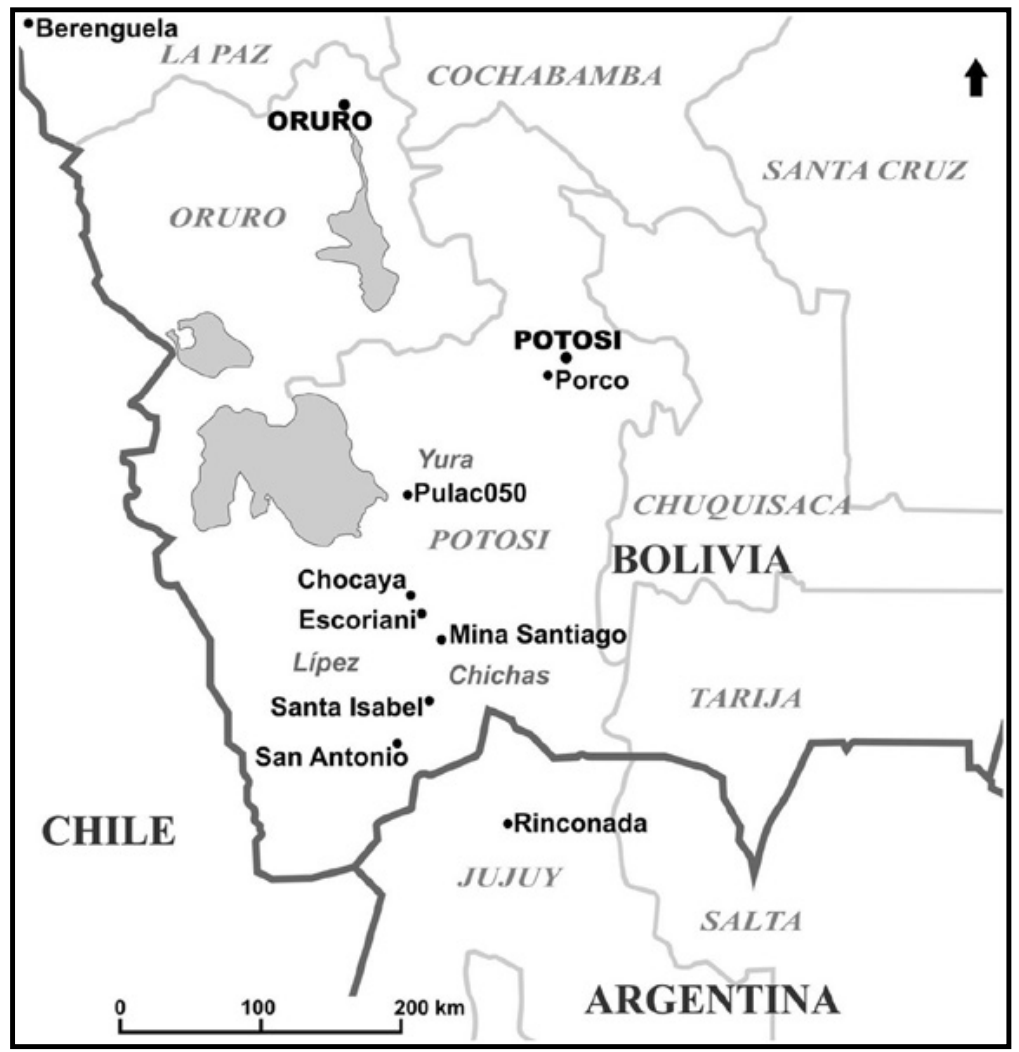

Figura 1. Mapa con la ubicación de los establecimientos e instalaciones metalúrgicas con hornos de reverbero referidos en el texto. 


\section{Los hornos de reverbero andinos en las fuentes coloniales}

De manera general, las informaciones proporcionadas por las fuentes documentales coloniales acerca de los hornos metalúrgicos andinos son limitadas, siendo las más numerosas aquellas que refieren a las wayras o wayrachinas, los famosos hornos de viento (Téreygeol y Cruz, 2014). Las informaciones sobre otros modelos de hornos no solo son menos cuantiosas, sino que, salvo contadas excepciones, son aun más imprecisas. Tal es el caso de los tocochimpos citados por el padre Álvaro Alonzo Barba, pequeños hornos con mufla utilizados por los metalurgos indígenas andinos para refinar el metal, ${ }^{1}$ de los cuales todavía no se han hallado testimonios materiales. Otras referencias aluden a otro modelo de horno pequeño, el cual fue utilizado de manera generalizada por los indígenas "guayradores" durante las décadas que siguieron el descubrimiento del Cerro Rico para refinar, en la intimidad de sus viviendas, la plata obtenida anteriormente en las wayras. ${ }^{2}$ Como nos cuenta Capoche (1959 [1585], pp. 100-111), el refinado que se realizaba en estos hornos era por copelación, proceso llevado a cabo mediante una capa de cendrada ubicada en la base de los mismos. ${ }^{3}$

1 “...Llámanse en esta provincia tocochimpos unos hornos semejantes a los que los plateros llaman muflas y a los en que se hacen los ensayes de las barras. Fúndense en ellos por cebillo metal rico en poca cantidad, y los indios los usaban para refinar solamente. Es su fábrica de este modo: hácese un horno redondo como los de reververación, pero apenas de vara de diámetro. Tiene dos puertas: la una pequeńa, adonde se puede acomodar el fuelle si se quisiere para abreviar la obra; grande la otra, enfrente de ésta, capaz a que por ella se pueda poner dentro del horno la mufla, que es como una media olla grande, partida desde la boca de alto a baxo, llena toda de agujeros por donde el fuego del carbón se comunica..." (Barba, 1770 [1640], p. 133).

2 Como varios otros, Garcilaso de la Vega (1985 [1609], p. 207) refiere al refinado de los metales obtenidos en las wayras: “...Después en sus casas, hacían las segundas o terceras [fundiciones] con los cañutos de cobre, para apurar la plata y gastar el plomo. Porque no hallando los indios los ingenios que por acá tienen los españoles (de agua fuerte y otras cosas) para apartar el oro de la plata y del cobre -y la plata del cobre y del plomo- la afinaban a poder de fundirla muchas veces...”. (Corchetes nuestros).

3 "...lo cual tornan a fundir y refinar en sus casas, en unos hornillos chicos a fuego manso. Y mientras dura el gastar
No obstante, al igual que las wayras, el uso de este tipo de horno de refinación fue, a partir de los años 15721574 , reemplazado progresivamente por el proceso de amalgamación con azogue. Al mismo tiempo de revertir la baja del mineral de Potosí, este reemplazo tecnológico permitió a la administración colonial un mayor control del beneficio del mineral, que hasta entonces se encontraba en manos indígenas, y contrarrestar el serio problema que representaba para los "Quintos Reales" la producción de plata de baja ley, o las prácticas de adulteración como el "encobrado", aspecto igualmente señalado por Capoche, ${ }^{4} \mathrm{y}$ numerosas otras fuentes. De hecho, la magnitud de este problema había conducido a que en 1571 se dictaminase en Potosí el castigo de los fundidores, indios o españoles, que incurrieran en este fraude, así como la orden de que en adelante todas las fundiciones de refinado se realizacen ante la supervicion de la autoridad colonial. ${ }^{5}$ Lamentablemente, el hecho de que

el plomo hace cierto humo y movimiento, y en quedando la plata pura y acendrada, libre de liga y mezcla, cesa el humo y movimiento, que llaman dar la vuelta, y queda la plata en gran fineza" (Capoche, 1959 [1585], pp. 100111).

4 "Pero los indios no esperaban (antes de los azogues cuando corría la plata corriente que eran pedazos y tejos) que hiciese [la fundición] todo su curso y punto, y así la quitaban del fuego con mucho plomo y cobre que le echaban, por no acudirles el metal como solía. Y así andaba en esta villa [Potosí] y reino la plata tan baja que la de esta provincia era de ochocientos y novecientos maravedís de ley...” (Capoche, 1959 [1585], p. 111). (Corchetes nuestros).

5 “... E después de lo susodicho en la dicha Villa Imperial de Potosí, quince días del dicho mes y año, el dicho señor corregidor dijo que por cuanto queriendo poner remedio en que ande buena plata y que no ande encobrada, y que para remedio dello su merced ha proveído, hoy dicho día, que en cada doctrina haya seis alcaldes para que cada uno dellos tenga cuenta con dos ayllos y con todos los chojadores y guairadores que hubiere, y la plata que fuere mala y encobrada la miren y la traigan [f. 171v] ante su merced con el indio que la tuviere, para que sea castigado, y que los dichos alcaldes visiten todos los días los dichos chojadores y guairadores con gran cuidado y porque lo susodicho haya buen efecto y se vea la plata que de aquí adelante se fundiere, mandaba y mandó que todas las personas desta dicha Villa, vecinos e moradores, estantes y habitantes en ella, españoles e indios, hagan fundir y fundan toda la plata menuda que tuvieren, la cual fundan de aquí al martes primero siguiente, so pena que el que no lo hiciere pierda la plata, aplicada por tercias partes, juez, cámara y denunciador, 
en Potosí estos hornos se hallasen en el interior de las precarias viviendas de los indígenas afectados a la labor de los metales, a diferencias de las wayras ubicadas en espacios retirados en las cumbres y filos de los cerros, fue la causa de que no se cuente hoy en día con testimonios materiales que permitan conocer su apariencia y modo de funcionamiento. Sin embargo, salvando la brecha temporal encontramos algunos indicios sobre la morfología de estos hornos en el asiento de San Antonio del Nuevo Mundo (San Antonio de Lípez), el cual tuvo su mayor desarrollo durante la segunda mitad del siglo XVII (Cruz et al., 2011). Se trata de un pequeño horno abovedado de contorno circular, con un diámetro en la base de aproximadamente $0.5 \mathrm{~m}$, construido en argamasa y piedras. De manera significativa, los restos de las paredes de la bóveda presentaban, en su lado interno, una impronta textil. El horno fue hallado en el interior de un recinto de una vivienda periférica del asiento minero, y habría sido utilizado para refinar metal de plata si tenemos en cuenta que el mismo presentaba en su base una capa de cendrada. Por otra parte, una idea más ajustada de la apariencia y funcionamiento de este tipo de horno, y de aquellos que en los primeros momentos de Potosí estuvieron destinados a refinar la plata producida en las wayras, es proporcionada en un trabajo de corte etnoarqueológico realizado por Van Buren y Mills (2005). El mismo trata sobre una pequeña instalación metalúrgica, ubicada en los alrededores de Porco, utilizada por el maestro Carlos Cuiza para refinar el plomo argentífero producido en sus wayras. En su labor de refinamiento, Cuiza utiliza un pequeño horno con cámara de reverberación, teniendo en su frente otra cámara para la alimentación en combustible y por detrás una chimenea. Para su funcionamiento, Cuiza reviste el piso de la cámara de reverberación con una capa elaborada con ceniza de yareta y orín, de aproximadamente $2 \mathrm{~cm}$ de espesor, sobre la cual coloca el plomo argentífero a refinar por copelación. Tal como lo señalan Van Buren y Mills, el modelo de horno de refinación de Cuiza es similar a los hornos "pacha-

y mandó se apregone públicamente en esta dicha villa en las calles acostumbradas della porque venga a noticia de todos...”. Orden que se dio en Potosí para que los indios no hiciesen fundiciones de plata y nombramientos de alcaldes que se hicieron en varias doctrinas, Potosí 15 de marzo de 1571 . BN/Ms 3040 fs. 167r-169v. (Transcripción nuestra). mancas" citados por Pfordte (1893, pp. 25-30) utilizados al menos hasta el siglo XIX por los indígenas de la región de Pasco igualmente para refinar plata.

Otra categoría de horno de reverbero, considerablemente más grande que los anteriores, fue empleado de manera generalizada en el espacio surandino tanto para la reducción de minerales argentíferos como para la posterior refinación del metal. El mismo también se compone de tres cuerpos bien diferenciados: una boca o cámara de alimentación, una cámara de trabajo y una chimenea, pudiendo variar sustancialmente en su morfología, dimensiones y materiales constructivos. Es sobre esta categoría de horno de reverbero que nos focalizaremos en este trabajo. Las informaciones proporcionadas por las fuentes documentales acerca de esta categoría de horno son generalmente más tardías que aquellas que refieren a las wayras y pequeños hornos de refinación evocados anteriormente, conocidos en su mayoría recién a partir de las primeras décadas del siglo XVII. Esta aparición tardía en las fuentes fue una de las razones que condujeron a adscribir esta categoría de horno a una tradición tecnológica europea. Sin embargo, como lo desarrollaremos a continuación, se trata de una categoría que no solo se desarrolló en los Andes, sino que varios de sus atributos relevan de una tecnología prehispánica.

Descripciones precisas acerca de esta categoría de horno de reverbero y sobre su modo de funcionamiento existen ya en los ańos 1618 en Oruro (Cobo, 1890 [1653]) y alrededor de 1626 en los Lípez (Barba, 1770 [1640]). De manera significativa, estas referencias muestran ya un lenguaje técnico bien definido, por lo que se puede deducir que tal tecnología se remontaría por lo menos a las últimas décadas del siglo XVI y primeras del XVII. De hecho, Luis Capoche (Barba, 1770 [1640], p. 129) refiere vagamente sobre un establecimiento metalúrgico en los Lípez alrededor de los años 1580, el cual, como veremos más adelante, guarda semejanza con el observado posteriormente por Cobo en Oruro, y que funcionaba con esta categoría de hornos. ${ }^{6}$

6 "En la comarca del cerro hay minas de cobre muy fino [diseminado] y algunas labradas por el Inca, y las minas de soroche con ley de plata y muchos colores finisimos, y un azul muy singular para pintores. Hay casa de fundicion [hornos de fundicion] [con] cinco hornazas, 
Es relevante también que para el cura secular Álvaro Alonso Barba, uno de los más avezados expertos en su época, estos hornos de reverbero, cuyo uso -señala- se hallaba por entonces muy difundido en las regiones de Chichas y Lípez (Barba, 1770 [1640], p. 138), representaban en sí una novedad. ${ }^{7}$ En este mismo sentido, Fernando de Montesinos da a entender algunos ańos más tarde que estos mismos hornos, utilizados ya de manera generalizada "en todo el Perú”, resultarían de una invención local. ${ }^{8}$ Asimismo, un documento de $1635,{ }^{9}$ que forma parte de un legajo esclesíastico de la Audiencia de Lima (AGI, Lima, 331), nos muestra un dibujo de este modelo de horno de reverbero y otro de un horno de tostado (Figura 2). El texto que acompańa estos dibujos refiere no solo que este modelo de horno reverbero es el usado en "todo" el Perú, sino que su conocimiento era "secreto", es decir, desconocido por los espańoles. El autor de este documento, del cual desconocemos aún su nombre, reclama el premio por desvelar este secreto. ${ }^{10}$ Por otra parte, Barba,

las cuatro para fundir y una para refinar". Capoche (1957[1585], p. 129).

7 "Poco o nada se ha usado hasta nuestros tiempos, entre los que han tratado de metales, el fundirlos en hornos de reverberación, y aunque antes de ahora se tuvo noticia de ellos, no fue con la perfección que hoy se usan, ni para este efecto, sino para refinar solamente" (Barba, 1770 [1640], p. 150).

8 "Con el gusto de haberse hallado modo de beneficiar el metal negrillo con quema, no se ha tratado de mejorar el horno en que se hace, y asi, aunque ha habido acerca de esto pareceres, se ha continuado con el primer horno que se inventó, sin ponerse en práctica otro. El horno que al presente sirve en todo el Perú para esta quema de negrillos, es á modo del de pan con su capilla, salvo que la lumbre se da en un poyo cubierto, pegado al mismo horno, y por una puerta se da la lumbre, y por otra del mismo poyo sale la ceniza; en medio tiene otra puerta que se comunica con el horno, y por ella entra la llama que reverbera por todo él, bańa la harina del metal, y la maleza que el fuego vuelve en humo sale por dos cañones que están frontero de la lumbre, y suben como una vara por cima de la capilla del horno; y este es el que ahora sirve como he dicho y se llama reverberación, porque da el fuego su actividad inmediatamente al metal" (Montesinos, 1638, pp. 278-279).

9 Dibujo de un horno para sacar la plata de los metales negrillos (AGI/27.14 MP-Ingenios, 148).

10 “ex. Señor Diego Rodriguez Mesina digo que el secreto que tengo offrecido por otros memoriales en raçon del aumento de la plata que se saca de los metales negrillos quien conocía muy bien los tratados metalúrgicos europeos, remarca en el modelo andino la existencia de una chimenea inclinada, muy probablemente por no aparecer en dichos tratados. ${ }^{11}$ También destaca el uso del soroche como fundente, un procedimiento utilizado igualmente por los metalurgos indígenas para procesar minerales ricos en plata en las wayras. ${ }^{12} \mathrm{Y}$ si bien en su "Arte de los Metales" relaciona en varias ocasiones esta categoría de horno con el uso de fuelles, da a entender también que se trata de una elección, pudiendo funcionar "en otras partes" solo con ventilación natural. ${ }^{13}$ En nuestra perspectiva, es muy probable que el uso de fuelles en estos hornos haya resultado de una adaptación colonial destinada a mejorar su rendimiento. De hecho, en la descripción que nos brinda Bernabé Cobo sobre el funcionamiento de estos hornos en Oruro en 1618 , es decir, ocho años antes de las observaciones de Barba en los Lípez, solo refiere al uso de fuelles

que se disponen con fuego para sacarla, lo declaro y pongo en manos de v. ex. firmado de mi nombre y sellado en este pliego para que Aviendose v. ex. servido de tomar asiento de premio que se me tiene de dar lo mande abrir para que se publique y salga a la luz el engaño tan grande y error que ay y avido en el saberle sacar la plata que tienen los metales negrillos y de la mas de el secreto digo ex. seńor que todo este secreto consiste en que la llama del fuego no toque en el metal quando se quema porque en los hornos de reberveracion, que son los que se usan en todo el piru son en los que se pierde la ley de los metales en mas cantidad de la mitad. este horno de reberveracion es el que tiene son a lado la $\mathrm{A}$. y el que esta la B. es el que se a de usar para quemar los metales porque en el no les toca la llama" (AGI/27.14 MP-Ingenios, 148, r).

11 "A los hornos de reverberación se añade una como cola a la parte opuesta a la ventana por donde la llama entra, que por la figura que representa y mucho metal que traga, llaman algunos dragón. Es la Chimenea que dijimos arriba, o como horno castellano, no derecho sino inclinado" (Barba, 1770 [1640], p. 136).

12 "Aunque yo en Chacapa, de la provincia de los Chichas echaba juntas de una vez en cada horno sesenta arrobas de plomo para fundir veinticuatro de metal rico del cerro de Trinidad de los Lípez" (Barba, 1770 [1640], p. 151).

13 "Para dar más fuerza al fuego, ponen en algunas partes (aunque en otras no se usa) fuelle en estos hornos cuando se funde en ellos. Dispónenlos de suerte que su sopolo abata la llama al baño, y de cualquier manera ayuda muchísimo, porque es el aire el alma a quien da fortaleza y mayor actividad al fuego" (Barba, 1770 [1640], p. 155). 
para extraer el plomo y la escoria en la etapa final de la refinación por copelación. Pero veamos en detalle el aspecto que tuvieron estos hornos de reverbero andinos y la manera en que fueron utilizados en las propias palabras de Bernabé Cobo:

La fundición por reverberacion se hace echando los metales en unos hornos de hechura de los de cocer pan, salvo que la boca por donde se les da fuego está poco más de un codo de alta del suelo del horno y hecho en ella un pequeño hornillo atravesado donde se echa la leña y se da fuego, cuya llama, entrando por la boca del horno adentro, baña todo su techo y bóveda, con cuyo calor se derriten los metales que están en el suelo debajo de la llama. En frente desta boca tiene el horno otra muy pequeña, de la cual comienza la chimenea, que sube algo más alta que el horno por donde sale el humo. Fuera de estas dos bocas lo demás está cerrado por todas partes mientras arde. Su suelo, si no es muy fuerte, lo desbarata con su peso el metal derritiéndose y se sume por él; á cuya causa lo hacen de una mezcla de huesos quemados y molidos, carbon y arena, la cual aprietan y apisonan con mazos de hierro, y para cada hornada ó fundicion de metal se hace nuevo suelos. Échanse los metales en este horno así como los sacan de la mina sin molerlos, que son piedras y guijarros como ó dos puños, mayores y menores, y suélense echar en cada hornada cincuenta quintales. Dáseles fuego sin cesar por cuarenta horas, poco más ó menos, la leńa que se quema es menuda, de rama, que levanta gran llama [...] Con este beneficio dan la plata que tienen todo género de metales, ricos y pobres, blandos y duros, sin que se pierda un tomin; sólo para que con facilidad se derritan y corran, se tiene cuidado de mezclar con los metales sacar el zoroche, que es metal plomizo, el cual, aunque suele ser pobre y de poca ley, todavía se funde á vueltas de los demás, para que les haga correo. La cantidad de plata que se saca con este beneficio es desigual, segun son ricos ó pobres los metales que se funden. De una hornada de crudíos que yo vi adulzar en Oruro el año de 1618, en que entraron cinco hornadas de primera calda y fundición, que echando á cada una á cincuenta quintales, venían á ser doscientos y cincuenta de metal bruto, se sacaron trescientos marcos de plata pura (Cobo, 1890 [1653], pp. 308-312).

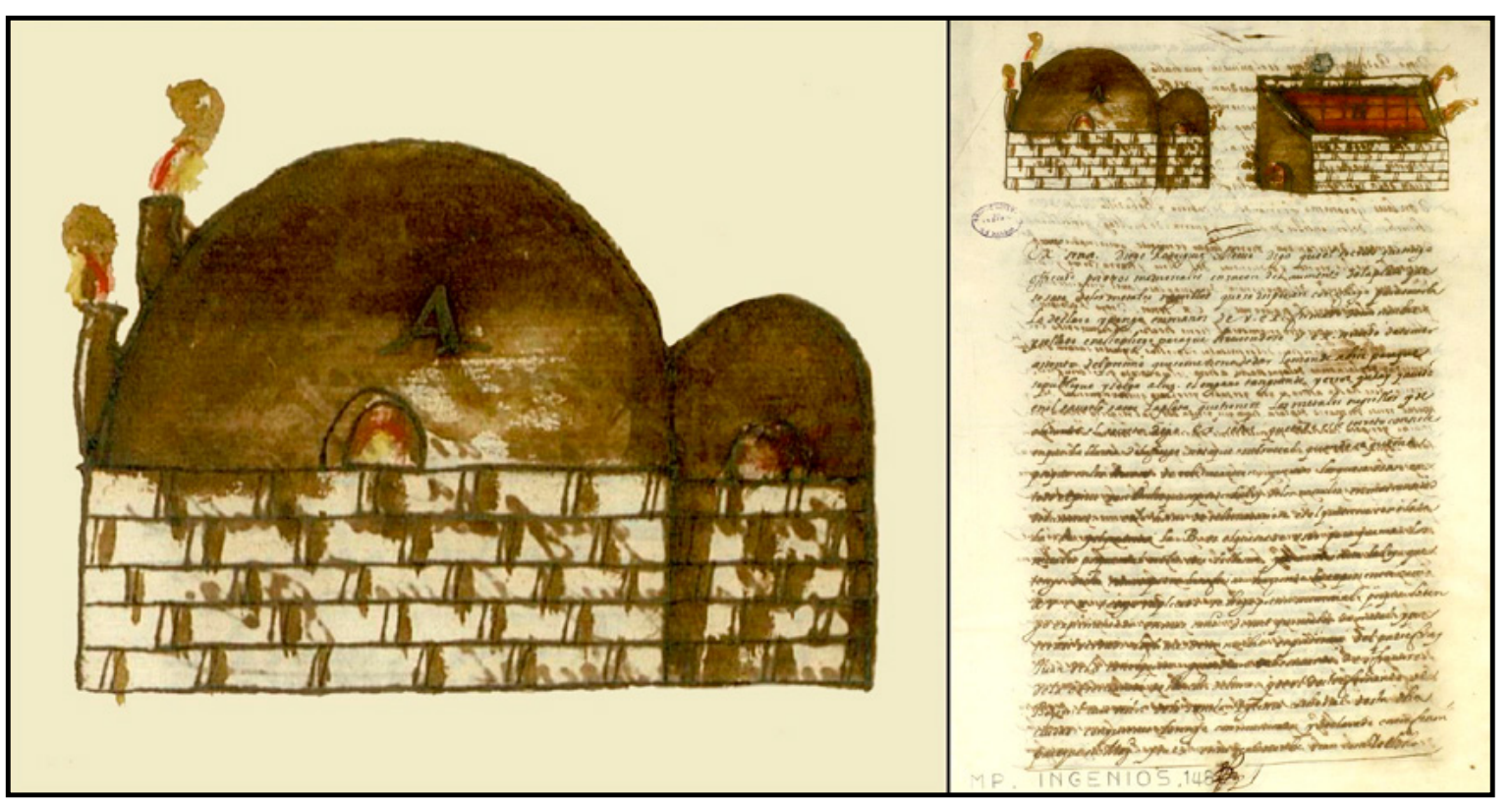

Figura 2. Dibujo de horno de reverbero en el documento de 1635 (AGI/27.14 MP-Ingenios, 148, r). 
Esta descripción de Cobo que transcribimos aquí in extenso da cuenta, en esta época aún temprana de la minería colonial, de una cadena de procedimientos técnicos bien definidos y establecidos. De su descripción también se destacan los rendimientos de cada etapa de fundición: 250 quintales de mineral bruto, en cinco horneadas, para producir una horneada de 50 quintales de crudío (entre 6 y 10 quintales por cada 50 de mineral bruto), los que una vez refinados darían 300 marcos de plata pura, alrededor de $69 \mathrm{~kg}$.

\section{Los registros de hornos de revebero en el espacio surandino}

En concordancia con las fuentes documentales que venimos de ver, los registros efectuados nos muestran que esta categoría de horno de reverbero andino, portando en frente una cámara de alimentación y por detrás una chimenea, fue replicado en las áreas mineras del espacio surandino (Potosí, Lípez, Chichas, Pacajes, etc.) por lo menos desde comienzos del siglo XVII. Por su excepcional estado de conservación se destacan los hornos registrados en Vila Punku Cueva, en Santa Isabel en Sud-Lípez. Se trata de dos hornos, uno de reducción y otro de refinación, situados, como su nombre lo indica, en el interior de un abrigo rocoso, el mismo ubicado en una estrecha quebrada. Los hornos fueron construidos con piedras y argamasa, el de reduccion más grande que el de refinación. En el caso del horno de reducción, su cámara de trabajo posee un diámetro de 2,3 $\mathrm{m}$ y una altura de $1 \mathrm{~m}$, mientras que la chimenea alcanza una altura de $1,3 \mathrm{~m}$. La solera del horno se encuentra inclinada 20 grados hacía una apertura ubicada de manera perpendicular a la circulación de las llamas, y cuenta con un agujero de colada de $4 \mathrm{~cm}$ de diámetro (Figura 3). A menos de $3 \mathrm{~m}$ de este horno se encuentra el segundo, el cual, salvo sus dimensiones diferentes, presenta la misma morfología. Su cámara de trabajo mide $0,82 \mathrm{~m}$ de diámetro con altura de la bóveda de $0.47 \mathrm{~m}$, es decir, con una capacidad tres veces menor que el horno de reducción $\left(0,5 \mathrm{~m}^{2}\right.$ contra $1,5 \mathrm{~m}^{2}$ para el horno de reducción). Aparte de su tamaño, se diferencia también del primero al presentar dos aperturas laterales en la bóveda. Finalmente, la solera, parcialmente conservada, se encuentra revestida de un capa blanquecina y polvorienta. El análisis por FRX de un fragmento de esta solera mostró una matriz en ceniza vegetal embebida en óxido de plomo. Estos resultados permiten afirmar que se trata de un horno de refinación por copelación (Téreygeol et al., 2016).

Testimonios de otros hornos de reverbero semejantes a los de Vila Punku Cueva, tanto de reducción como de copelación -estos siempre más pequeños-, fueron registrados en dos sectores metalúrgicos cercanos a Santa Isabel. Entre ellos se destaca un pequeño horno de copelación comportando una solera con dos receptáculos, característica que como veremos más adelante hemos hallado también en estructuras de combustión prehispánicas. Otros testimonios de esta categoría de horno de reverbero fueron registrados, de manera dispersa, en las regiones de Chichas y Sud-Lípez (Figura 4), en el asiento de Chocaya, en la localidad de Escoriani, en mina Santiago y en San Antonio del Nuevo Mundo, como también en Potosí y en Berenguela de Pacajes. En Chocaya se identificaron los restos correspondientes a las chimeneas de dos hornos en cercanía de las antiguas explotaciones mineras, en la periferia del actual pueblo. En Escoriani, un paraje ubicado en el corazón de la región minera de Chichas, entre las minas de Chocaya, Chorolque, Tatasi y Portugalete, se registraron, en el interior de una quebrada despoblada, los restos de cinco instalaciones metalúrgicas comportando cada una de ellas entre uno y más de tres hornos. En todos los casos se trata de hornos de gran porte, con cámaras de trabajo de entre 1,5 y 2 $\mathrm{m}$ de diámetro. Un rasgo significativo de estas instalaciones es la presencia en superficie de abundantes restos de argamasa, elementos estructurales de estos hornos, mostrando en uno de sus lados improntas irregulares de textiles. Asimismo, en San Antonio del Nuevo Mundo se identificaron los restos de 11 hornos, todos ellos construidos con piedras y argamasa con dimensiones semejantes a los anteriores. Por su parte, en Kalarqa-Mina Santiago, un paraje ubicado junto a la ruta que comunica Tupiza con Atocha, a unos $15 \mathrm{~km}$ al sureste de Escoriani, se registró una instalación comportando un conjunto de cinco hornos, cuatro de ellos de reducción de grandes dimensiones y uno de refinación considerablemente más pequeño, todos ellos emplazados linealmente en el interior de un recinto. Regresaremos más adelante sobre ella. Otra instalación 


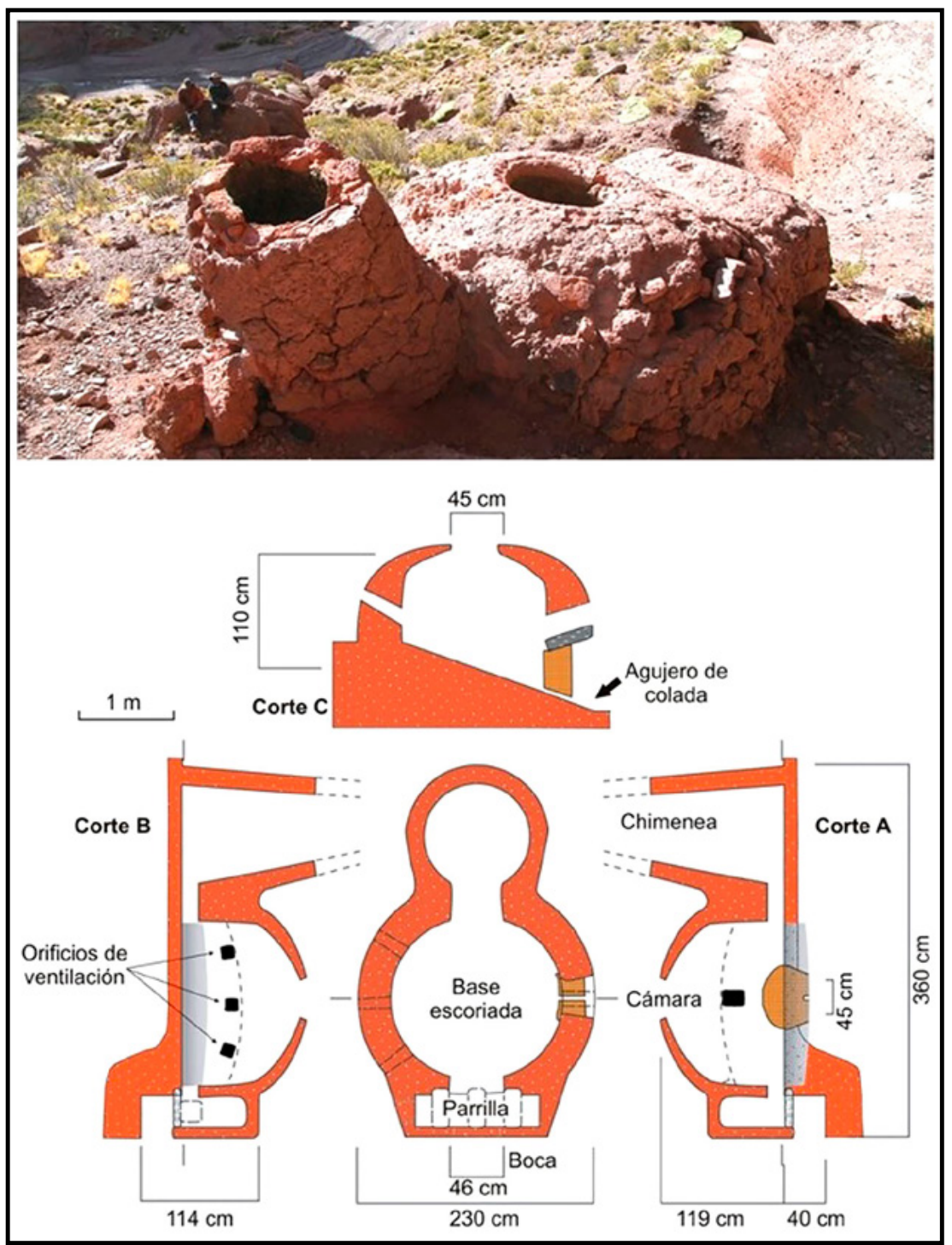

Figura 3. Fotografía y relevamiento del horno de reverbero registrado en Vila Punku Cueva, Santa Isabel.

con hornos de reverbero fue igualmente registrada en cercanías de Potosí, sobre una explanada ubicada en la cumbre del cerro Guaynacabra. En el sitio, situado a solo $200 \mathrm{~m}$ de un sector metalúrgico inkaico donde se hallaron abundantes fragmentos de wayrachinas, se registraron los contornos de dos hornos de reverbero, cuyas cámaras tuvieron un diámetro máximo de $1,5 \mathrm{~m}$. Junto a los hornos se encontraron los restos de varios recintos derruidos, así como abundantes fragmentos de cerámicas con estilos prehispánicos y de comienzos de la Colonia. De manera significativa, la ubicación y característi- cas del sitio se corresponden con la descripción de Nicolás del Benino (1965 [1573]) sobre las instalaciones que Gonzalo Pizarro utilizó para beneficiar, en vano según la fuente, el mineral del cerro de Potosí, poco tiempo antes de su descubrimiento oficial en $1545 .{ }^{14}$ De ser así, se trataría de uno de

14 "Y como esta provincia en aquel tiempo tenía fama de haber en ella minas ricas de plata, por razón de las de Porco, Gonzalo Pizarro las procuraba con mucha instancia, ansí por medio de los indios como por medio de españoles y criados suyos que las buscaban; y andando en esto, vino a su noticia como a una falda del cerro de 


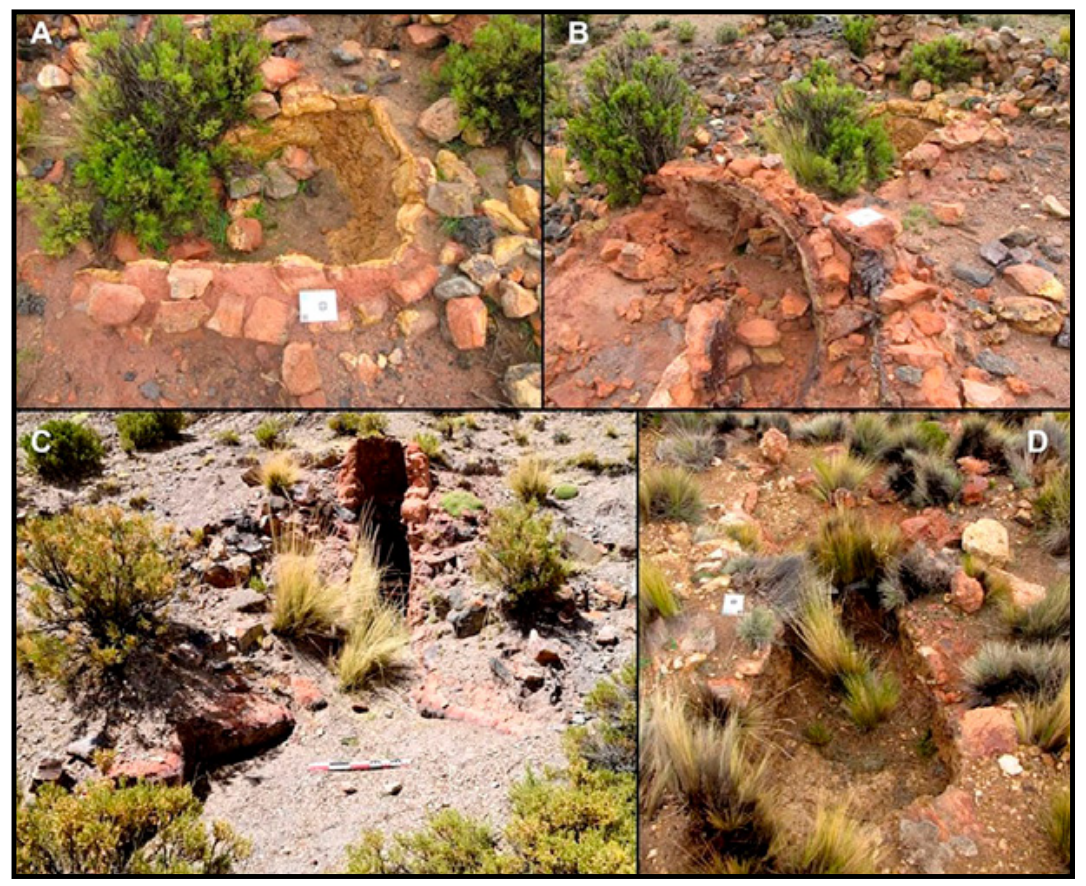

Figura 4. Fotografías de antiguos hornos de reverbero registrados en la región de Chichas.

A y B. Escoriani; C. Mina Santiago; D. Chocaya.

los antecedentes más tempranos de esta categoría de horno. Un horno de aspecto sustancialmente distinto fue registrado en Berenguela de Pacajes, en un contexto de comienzos de la Colonia marcado por abundantes restos de cerámicas de estilo Inka Pacajes y Qolla Tardío II (Cruz y Téreygeol, 2014). Como en los casos anteriores, se trata de un horno de reverberación construido con piedras y arcilla compuesto de tres cuerpos: cámara de fuego, cámara de trabajo y chimenea. Pero a diferencia de los otros, el horno presenta una chimenea y base de cámara de trabajo de contorno rectangular. También se destaca por su mayor tamaño, teniendo como dimensiones máximas 4,20 $\mathrm{m}$ de largo, $2 \mathrm{~m}$ de ancho y 3,2 $\mathrm{m}$ de alto (chimena) (Figura 4). Testimonios de hornos de reverbero semejantes fueron identificados por otros

Potosí, por la parte del Poniente, se habían descubierto unas vetas de metal de plata, y luego fue a ellas, y vistas, mandó hacer allí unos buhíos donde se pasó y llevó aderezos para labrarlas y para fundiciones, donde las labró cierto tiempo y el metal que halló fue de poco o ningún efecto; en cuyo asiento hoy en día se parecen los paredones altos de los edificios que hizo, que son aquellos que Vra. Ex. a vida desde lo alto del cerro de Potosí" (Nicolás de Benino, (1965 [1573], p. 364). investigadores en el centro minero de Porco (Van Buren y Mills, 2005; Weaver, 2008; Van Buren y Cohen 2010), en la región de Cinti (Rivera Casanovas, 2008) y en distintas localidades de la puna jujeña (Angiorama y Becerra, 2010; Becerra et al., 2014).

En el sur de Bolivia, los sitios metalúrgicos que funcionaron con esta categoría de horno pueden diferenciarse en: (A) pequeñas instalaciones localizadas en centros mineros comportando uno o dos hornos de reverbero (Chocaya, San Antonio de Lípez), (B) instalaciones y pequeños establecimientos, con dos y más hornos dispersos, en parajes alejados de los centros mineros (Vila Cueva Punku, Santa Isabel, Escoriani, Potosí, Berenguela) (Figura 5) y (C) establecimientos comportando un conjunto de hornos alineados (Kalarq'a - Mina Santiago), este último igualmente identificado en la puna de Jujuy en el sitio Fundiciones II, el cual fue adscrito a la segunda mitad del siglo XVIII (Becerra et al., 2014). Los dos primeros casos guardan en común el encontrarse ubicados en parajes visualmente discretos, como Vila Punku Cueva oculta al interior de una estrecha quebrada, característica que entendemos se 


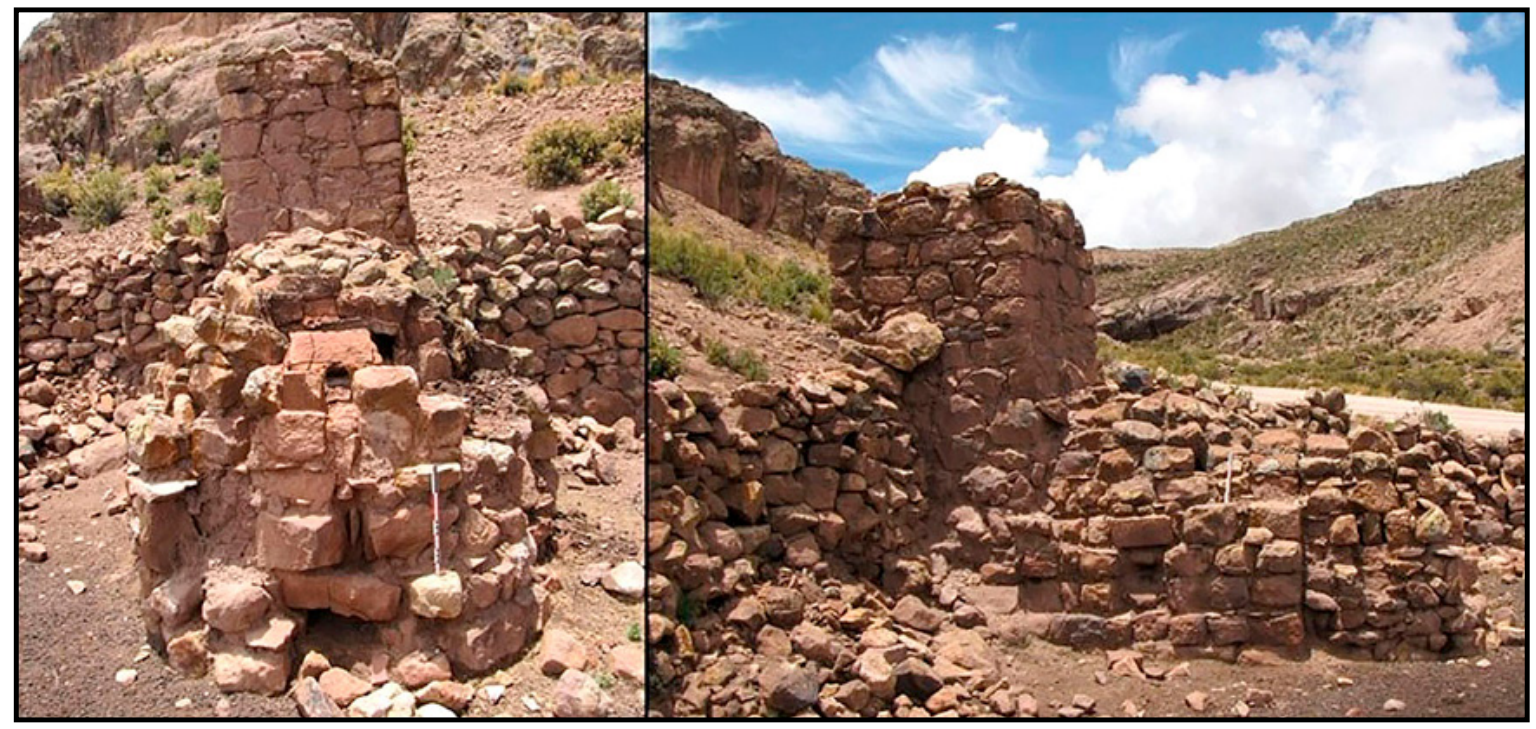

Figura 5. Fotografías del horno de reverbero registrado en Berenguela de Pacajes.

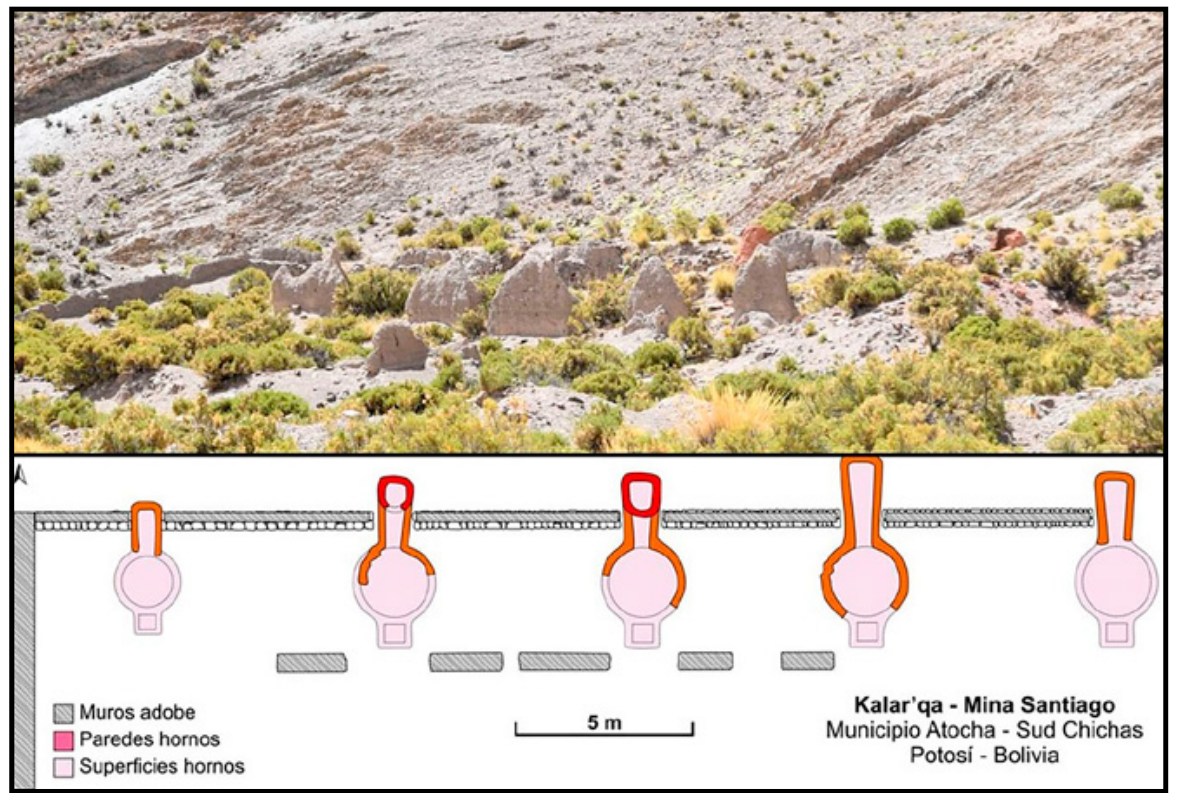

Figura 6. Fotografía y croquis de planta del establecimiento con hornos de reverbero de Kalar'qa - Mina Santiago.

encontraría relacionada, en contraposición con los 'Hornos Reales' establecidos en los principales centros mineros, con la producción clandestina de plata no quintada (Cruz y Téreygeol, 2016). Por su parte, el establecimiento identificado en Kalarq'a - Mina Santiago (Figura 6) nos remite directamente a las instalaciones que Cobo pudo ver en funcionamiento en Oruro en 1618 , lo mismo que a la referencia de Capoche sobre una instalación semejante en las cercanías de Escalla en los Lípez, la cual en todo caso sería anterior a 1580. Considerando estas referencias y los datos del sitio Fundiciones II en la puna de Jujuy, vemos que estas instalaciones se extendieron sobre una gran parte del espacio surandino (Oruro - Puna de Jujuy) desde al menos los años 1580 hasta la segunda mitad del siglo XVIII). 
Ahora bien, un antecedente prehispánico directo de esta categoría de hornos de reverbero lo hallamos en el sitio de Pulac050, un establecimiento metalúrgico localizado a $10 \mathrm{~km}$ de las minas y centro minero de Pulacayo (Potosí, Bolivia), fechado entre los siglos IX y XIII (Cruz, 2010; Lechtman et al., 2011). ${ }^{15}$ Actualmente, los estudios y excavaciones realizadas en Pulac050 permitieron identificar cuatro sectores metalúrgicos bien diferenciados, registrando los restos de al menos 46 hornos y estructuras de combustión metalúrgicas. Entre los sectores estudiados se destaca una plataforma de trabajo, el Sector 1, la cual estuvo estructurada en torno a un horno (H1) que presenta características insospechadas en la metalurgia andina prehispánica, tanto en lo que refiere a su complejidad y tecnología como a sus grandes dimensiones. Este horno se compone de dos segmentos, H1A y $\mathrm{H} 1 \mathrm{~B}$, presentando el primero de ellos un mejor estado de conservación al hallarse semienterrado. El segmento H1A se compone de una cámara de fuego semienterrada, de forma rectangular, con paredes de piedras, sobre la cual se ubican dos banquetas suspendidas y atravesadas por conductos tubulares. Por su parte, el segmento $\mathrm{H} 1 \mathrm{~B}$ comporta una estructura de planta semicircular, con un diámetro máximo de $2 \mathrm{~m}$ y delimitada en su base por un pequeño muro de piedras y segmentos de sedimento intensamente rubificados. La misma se encuentra ubicada en un nivel superior que $\mathrm{H} 1 \mathrm{~A}$, conteniendo en su interior una capa gruesa (entre 0,20 y $0,30 \mathrm{~m}$ ) compuesta por elementos estructurales de tierra cocida y sedimento intensamente rubificado, la cual correspondería a una cobertura superior derrumbada. Perfiles obtenidos en los muros laterales de este segmento indican que el mismo, al igual que el segmento H1A, tuvieron una cubierta de forma abovedada. Ambos segmentos se encuentran conectados entre sí por un plano inclinado ubicado a nivel central de H1A (entre las dos banquetas suspendidas), el que presenta una intensa rubificación. Asimismo, en el muro lateral norte del cuerpo $\mathrm{H} 1 \mathrm{~B}$, se registró un conducto de ventilación orientado en sentido esteoeste, que comunicaba el exterior con la cámara de fuego. La apertura externa de este conducto se encuentra orientada al noroeste a fin de captar los vientos dominantes. Estas características señalan

15 El sitio es estudiado desde 2006 por P. Cruz y H. Lechtman en el marco del Proyecto Arqueológico Pulacayo. que se trata de un modelo prehispánico de horno de reverbero que funcionó con ventilación natural (Figura 7). Bien que formando parte de un mismo horno, los cuerpos H1A y H1B desempeñaron diferentes funciones metalúrgicas. En el cuerpo $\mathrm{H} 1 \mathrm{~A}$ se encuentra la boca de alimentación de combustible, la cámara de fuego y dos banquetas con conductos sobre las cuales se desarrollaron muy probablemente operaciones de metalurgia secundaria. Por su parte, el segmento H1B fue una cámara de trabajo de planta circular y cubierta abovedada, semejante a la de los hornos de reverbero coloniales. Si bien no se registraron testimonios materiales, muy probablemente el horno contaba también con una chimenea conectada con el segmento H1B, del cual solo se conservaron los niveles inferiores.

Por otra parte, alrededor del horno $\mathrm{H} 1$ se identificaron los restos de al menos otras ocho estructuras de combustión metalúrgicas de menor tamaño. Entre ellas destacamos aquí los restos de una estructura (HA) de forma semiovalada de $0.9 \mathrm{~m} \times 0.4-0.5 \mathrm{~m}$, elaborada con argamasa y presentando dos receptáculos en su interior. Un perfil adyacente a la misma reveló que la estructura comportaba originalmente una cobertura de forma abovedada. Las dimensiones y características de esta estructura descartan su utilización en la metalurgia extractiva, siendo en muchos aspectos semejantes a los pequeños hornos de reverbero coloniales con solera y capa de cendrada observados en Santa Isabel (Figura 8). Asimismo, resulta relevante el registro en este sector de Pulac 050 de numerosos restos de paredes de argamasa, intensamente rubificadas, comportando en sus lados internos improntas textiles muy similares a las observadas en instalaciones metalúrgicas en Escoriani y en San Antonio del Nuevo Mundo (Figura 9).

En las columnas a continuación, se muestran aquellas semejanzas formales entre las estructuras metalúrgicas identificadas en el sitio prehispánico $\mathrm{Pu}$ lac050 (siglos IX-XIII) y en aquellas instalaciones coloniales registradas en las regiones de Chichas y Lípez, las cuales ponen en evidencia algunas continuidades tecnológicas. 


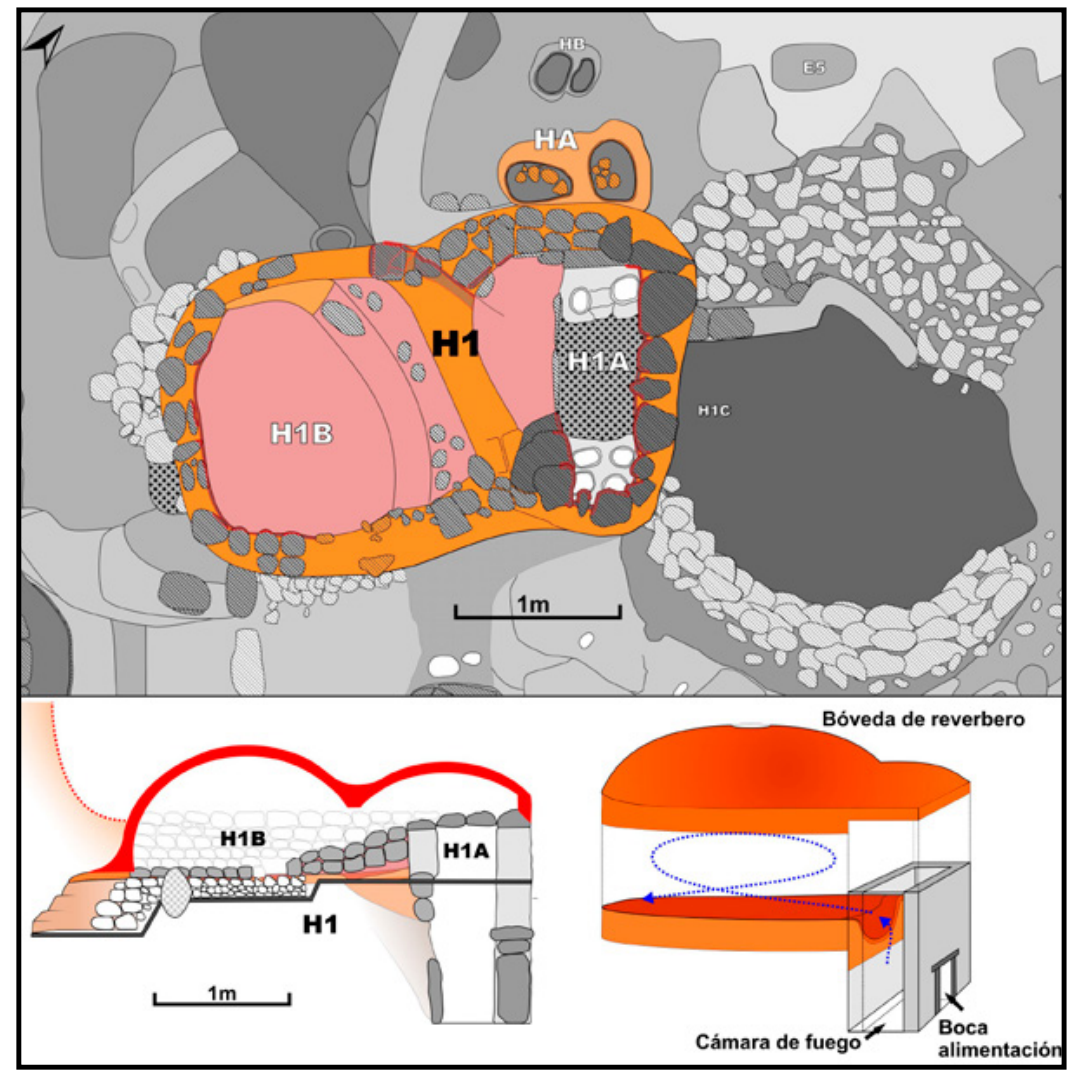

Figura 7. Sitio Pulac050, Sector 1. Arriba: relevamiento de planta de donde se destacan el horno H1 y la estructura HA. Abajo izquierda: perfil del horno $\mathrm{H} 1$ indicando la forma y ubicación probable de su cubierta abovedada, y posible ubicación de una chimenea. Abajo derecha: croquis del horno H1 mostrando su funcionamiento.

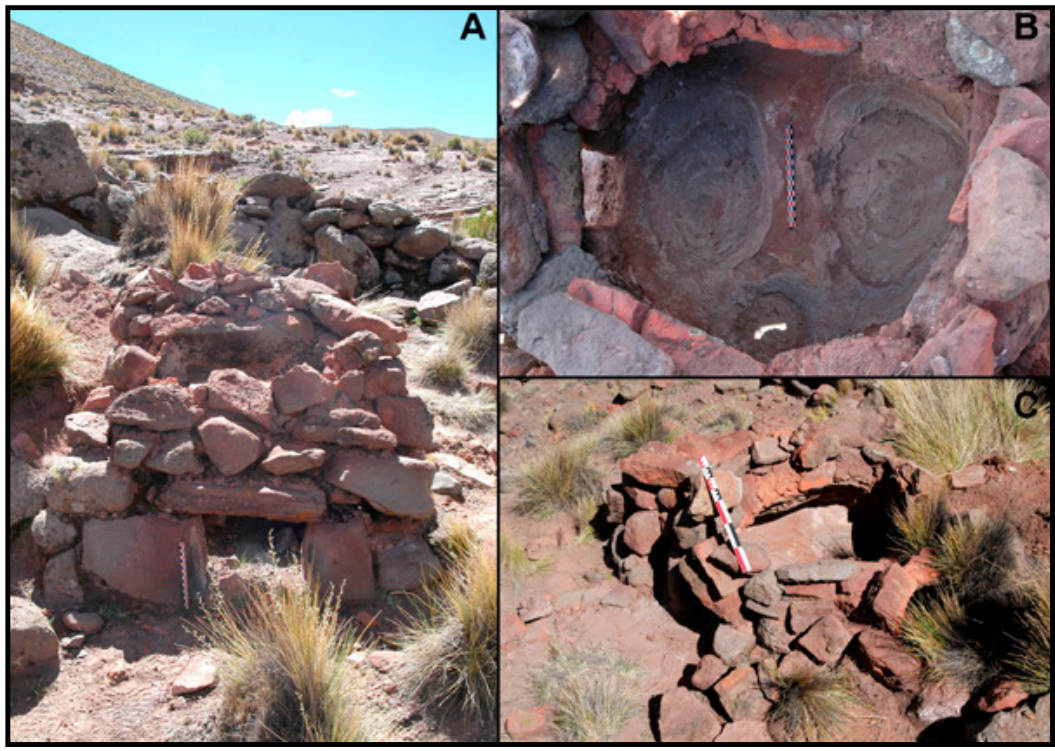

Figura 8. Fotografías de hornos de refinación registrados en Santa Isabel. Los mismos comportan una solera con capa de cendrada con dos receptáculos. Las fotografías A y B corresponden a un mismo horno, y la C a otro semejante. 


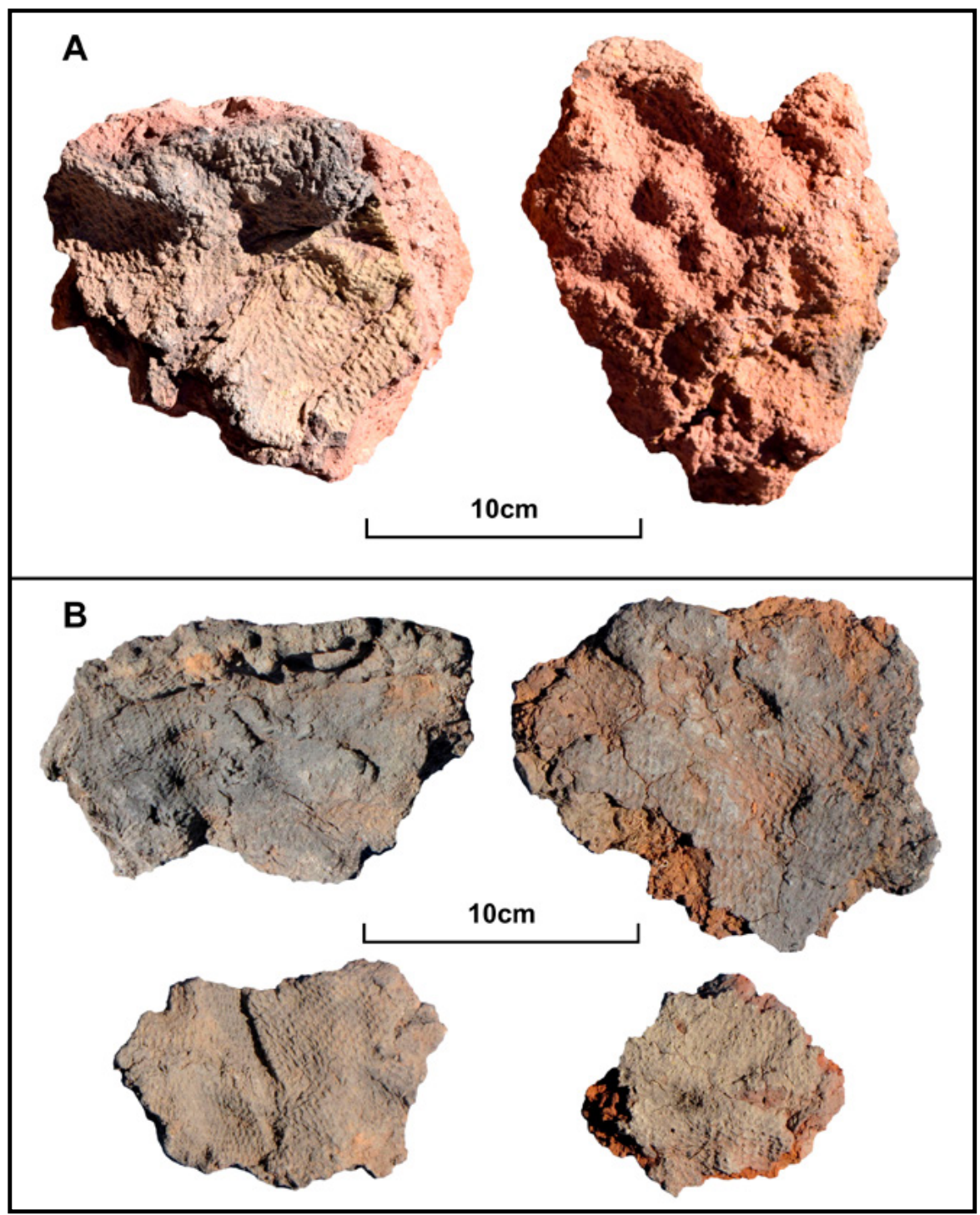

Figura 9. Fotografías de fragmentos estructurales de hornos en argamasa comportando en su lado interno improntas de textiles. Arriba: fragmentos hallados junto a los hornos coloniales de Escoriani. Abajo: Fragmentos semejantes registrados en el establecimiento metalúrgico prehispánico de Pulac050 (Sector 1). 


\section{Pulac 050}

Horno H1: horno de reverbero de grandes dimensiones compuesto al menos por dos segmentos diferenciados y comunicados entre sí (cámara de fuego con banquetas suspendidas y cámara de trabajo de planta semicircular. Probablemente el horno contaba también con una chimenea. El horno funcionaba con combustible de leños (tola) y ventilación natural.

Horno H1: conducto de ventilación que comunicaba el exterior con la cámara de fuego. El conducto se encontraba orientado para recibir los vientos dominantes.

Estructura HA: estructura de combustión metalúrgica de tamaño considerablemente menor al horno $\mathrm{H} 1$, con cubierta abovedada y comportando en su interior una solera $(0.9 \times 0.5 \mathrm{~m})$ con dos receptáculos. Se trata probablemente de los restos de un pequeño horno de reverbero destinado a operaciones de refinación. Sector 1: abundantes fragmentos estructurales en argamasa comportando impronta textil en su lado interno.

\section{Establecimientos coloniales}

En todos los establecimientos coloniales señalados: hornos de reverbero de grandes dimensiones compuestos de tres segmentos diferenciados y comunicados entre sí (cámara de fuego, cámara de trabajo de planta circular o semicircular, chimenea). Los hornos funcionaban con combustible de leńos y ventilación natural.

Escoriani: fragmentos de conductos de ventilación y paredes con orificios asociados con restos de hornos de reverbero.

Santa Isabel: pequeño horno de reverbero destinado a la refinación por copelación. El horno presenta un piso de solera $(0,65 \times 0,7 \mathrm{~m})$ y capa de cendrada comportando dos receptáculos.

Escoriani, San Antonio: abundantes fragmentos estructurales en argamasa comportando impronta textil en su lado interno.
No podemos obviar aquí que, en su detallado estudio sobre los hornos de reverbero de Porco, Van Buren y Cohen (2010) sostienen que se trata de una tecnología de origen europeo. Es sin duda muy probable que algunos de los hornos estudiados por estas investigadoras en el sitio, uno de los primeros asentamientos de espańoles en la región, releven de una tecnología europea. De hecho, sabemos que los Hornos Reales que funcionaron algunas décadas después en Potosí siguieron un modelo europeo. Asimismo, en Thola Pampa, un establecimiento metalúrgico colonial, pero que funcionó hasta el siglo XIX, hemos registrado los restos de al menos cuatro hornos de reverbero muy semejantes a los descritos en las fuentes europeas. No obstante, al menos dos hornos de reverbero estudiados por Van Buren en Porco presentan semejanzas formales con el horno $\mathrm{H} 1 \mathrm{del}$ sitio prehispánico Pulac050. Se trata de los hornos UR10 y UR11 excavados en el sitio Uruquilla, los cuales poseen una planta en la que se distinguen dos cuerpos, uno de ellos de forma más o menos ovalada y el otro, rectangular. Tal como lo señalan estas investigadoras, el primer cuerpo correspondería a la cámara de trabajo con bóveda de reverbero y la segunda a una cámara de fuego. Por su parte, el horno H1 de Pulac050 presenta una planta similar en la que se distinguen dos cuerpos, uno de ellos ovalado y que correspondería a una cámara con bóveda de reverbero, y el otro rectangular, siendo igualmente una cámara de fuego. Más aún, el horno UR11 de Uruquilla presenta en la base de la cámara de fuego una banqueta con conductos, la cual fue interpretada como una grilla (Van Buren y Cohen, p. 41). Esta banqueta es muy similar a las dos banquetas con conductos que se hallan igualmente en la cámara de fuego del horno H1, pero a diferencia del horno UR11, estas se encuentran suspendidas. Es evidente que los dos hornos de Uruquilla estudiados por Van Buren y Cohen y el horno H1 de Pulac050 relevan un mismo modelo de horno de reverbero. Pero mientras los dos hornos de Uruquilla se inscriben en un contexto colonial, siendo el horno UR11 datado por arqueomagnetismo en 1675-1760 (Van Buren y Cohen, p. 41), el horno H1 de Pulac050 se encuentra inserto en una compleja plataforma metalúrgica datada por tres fechados AMS entre 1140 y $610 \mathrm{BP},{ }^{16}$ es decir, al

16 Respectivamente $610 \pm 30$ BP (Beta-331427), $940 \pm 30$ BP (Beta-331428) y 1140 BP (Beta-331429). 
menos cinco siglos anteriores a los hornos de Porco. Y si bien la planta de estos hornos se acerca, tal como lo señalan Van Buren y Cohen (2010, p. 36), a la dibujada por Biringuccio (1990 [1540], p. 40), las banquetas con toberas, inexistentes en la metalurgia europea, son igualmente muy semejantes a las halladas en algunos hornos cilíndricos de Quillay, un establecimiento metalúrgico inkaico (Spina y Giovannetti, 2014). En este sentido, no es un dato menor que Porco haya sido una importante mina del Inka, hallándose cerámicas con estilos incaicos incluso en los contextos metalúrgicos coloniales estudiados por Van Buren y Cohen (2010, p. 39). Finalmente, es importante señalar que en los Andes prehispánicos, al igual que en Europa y otras partes del mundo, los hornos con bóveda de reverbero no solamente fueron utilizados en la producción de metales. Un ejemplo de ello son los más de 50 hornos prehispánicos hallados en La Troya (Catamarca), cuya planta en forma de gota indica que tuvieron también una cámara abovedada separada de una antecámara, fueron utilizados para la producción de piezas cerámicas (Feely 2011). La planta de estos hornos alfareros es muy similar a la de algunas estructuras de combustión metalúrgicas registradas en Pulac050, y guarda también semejanzas con los hornos de Quillay (Spina et al., 2017).

Sintetizando, si los registros efectuados en Pulac050 demuestran que los metalurgos andinos prehispánicos conocían y utilizaban la tecnología de los hornos con cámara de reverbero, las semejanzas formales que hemos visto nos señalan que muchos de estos saberes metalúrgicos prehispánicos continuaron vigentes durante el régimen colonial. Tal continuidad tecnológica resulta coherente en la medida de que los hornos andinos se encontraban ya adaptados tanto a la naturaleza de los minerales locales como a las condiciones ambientales, optimizando en ello tanto el consumo en combustible como el accionar del viento en lugar de fuelles. Muy probablemente tuvo también que ver que, a diferencia de contextos muy específicos, como los Hornos Reales, el grueso de las operaciones metalúrgicas se mantuvo en manos de indígenas especializados, como los yanaconas wayradores y los chojadores de los primeros años de Potosí (Cruz y Téreygeol, 2014).

\section{El programa de experimentación}

Un programa de arqueología experimental fue llevado a cabo con la finalidad de comprender mejor el funcionamiento de esta categoría de horno de reverbero andino y encontrar respuestas a algunos interrogantes relativos a su construcción. El programa se desarrolló en dos fases, la primera ejecutada en la plataforma experimental de Melle (Francia) y la segunda, en Tilcara (Argentina).

\section{Fase experimental 1}

Por razones técnicas, el modelo recreado fue una reproducción a escala 2:3 del horno de reducción observado en Vila Cueva Punku en Santa Isabel. Las dimensiones del horno fueron 2,5 $\mathrm{m}$ de largo (3,6 m el original) por 1,3 $\mathrm{m}$ de ancho (2,3 m el original). El horno constó de tres espacios interconectados entre sí por aperturas de $0.25 \mathrm{~m}$ de ancho y $0,15 \mathrm{~m}$ de alto. El primero es una cámara de fuego con dos niveles: el superior para el fuego en sí mismo, y el inferior, un cenicero que al mismo tiempo aseguró la ventilación del conjunto. Una parrilla de piedra fue colocada en la interfaz de ambos niveles. El segundo espacio concierne a la cámara de trabajo de reverbero, con un diámetro interno de $0,75 \mathrm{~m}$ y una altura bajo la bóveda de $0,55 \mathrm{~m}$. En la parte superior de la bóveda, una abertura de $0,4 \mathrm{~m}$ de diámetro permitió la introducción de mineral. Lateralmente, en el eje de las cámara se ubicó una apertura en la base con un agujero de colada de $4 \mathrm{~cm}$ de diámetro. Tres aperturas, de $10 \times 10 \mathrm{~cm}$ fueron puestas, de acuerdo con el modelo original, frente a la puerta. La solera es plana, con una pendiente de 20 grados en dirección del orificio de colada. La chimenea alcanzó una altura de $1 \mathrm{~m}$ presentando una forma cónica con una base de $0,40 \mathrm{~m}$ de diámetro interno. Para comprobar la temperatura durante las experimentaciones, se colocaron cinco termocuplas en distintas partes de la cámara de trabajo. Cada termocupla llegó hasta $1 \mathrm{~cm}$ en la atmósfera de la cámara y se realizaron registros cada 15 minutos. Para la puesta en funcionamiento del horno se utilizaron troncos de madera de $0,5 \mathrm{~m}$. Luego, una vez alcanzada la temperatura de trabajo, se utilizaron piezas más pequeñas de madera a fin de producir una combustión más rápida. El mineral utilizado fue una galena 


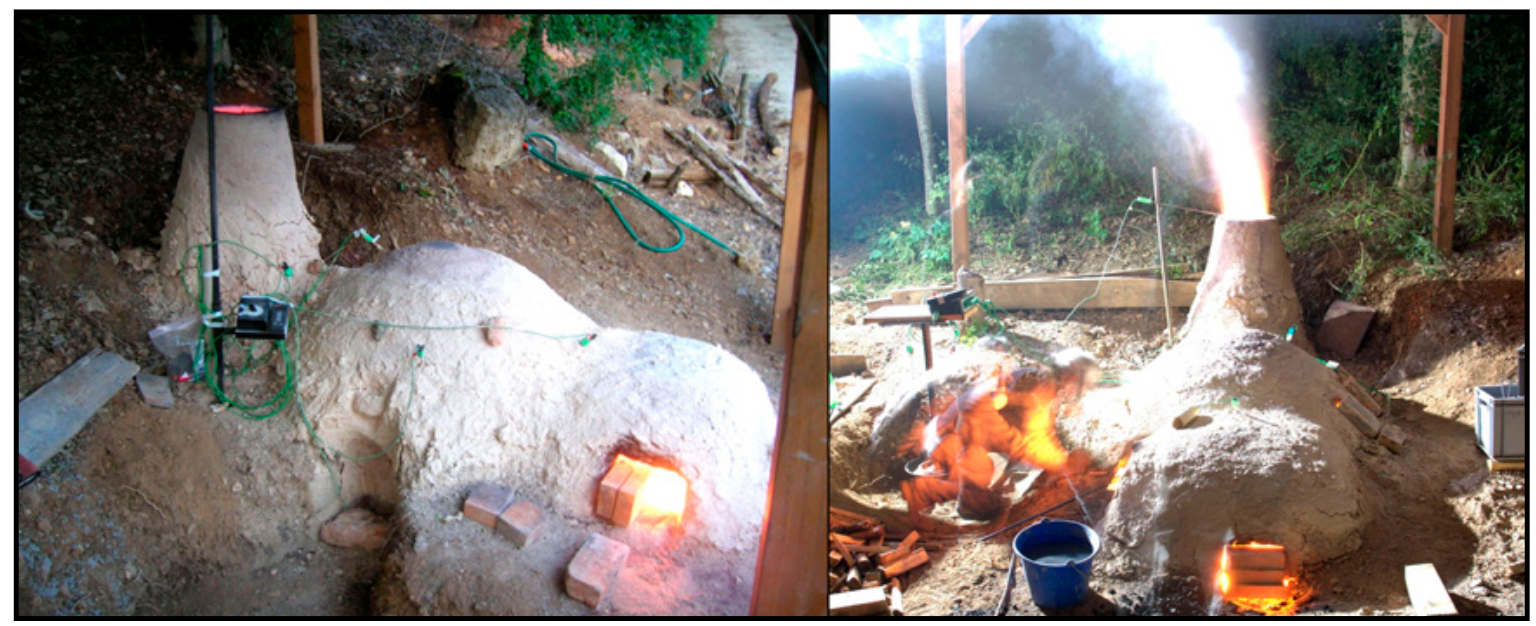

Figura 10. Fotografía del horno de reverbero experimental en funcionamiento.

El mismo es un modelo a escala del horno de reducción registrado en Vila Punku Cueva.

argentífera ligera con amplias gamas de calcopirita. Los 11 experimentos llevados a cabo con galena, que contabilizaron un total de 87:20 horas, permitieron obtener un modelo de funcionamiento de este tipo de horno (Figura 10).

El proceso de fundición en este modelo de horno fue el que se describe a continuación. Antes de su calentamiento, el mineral fue colocado sobre la solera, cerca de la base de las tres aperturas. El mineral fue molido hasta alcanzar las dimensiones de un grano de avellana $(15-25 \mathrm{~mm})$. Según el grado de secado del horno, el aumento de la temperatura fue más o menos rápido. Fue necesario un promedio de dos horas para que todas las termocuplas señalaran una temperatura superior a $700{ }^{\circ} \mathrm{C}$, momento en que se inició la fase de tostado. Esta fase, que tuvo dos horas de duración, se puso en evidencia por la emanación de un humo blanco con un claro olor a sulfuro. Luego, se aumentó el fuego remplazando los troncos por pequeños palos, logrando alcanzar al término de otras dos horas los $1000^{\circ} \mathrm{C}$ en la cámara de reverbero. Al descorchar el agujero de colada se pudo comprobar una primera fundición del mineral de plomo. Asimismo, la reacción del plomo con la arcilla produjo una escoria vítrea de color negruzco y la vitrificación de las paredes del horno. La temperatura de $1000{ }^{\circ} \mathrm{C}$ se mantuvo durante tres horas, lo que permitió la acumulación del metal fundido frente al agujero de colada. La evacuación por este orificio del plomo argentífero obtenido marcó la conclusión de la fase de reducción. Después de esta primera fundición, se redujo la temperatura del horno nuevamente al rango de tostado. Posteriormente se ańadió una nueva carga de mineral de galena dando inicio a un nuevo ciclo de reducción.

Esta serie de pruebas permitió constatar que el horno de reverbero funcionó de manera efectiva "tostando y reaccionando", obteniendo en cada fundición un plomo de trabajo listo para ser refinado. El plomo se acumuló limpiamente y la escoria equivalente a un vidrio plomífero pudo ser evacuada sin interrumpir la fundición. Las pruebas mostraron que el horno puede funcionar con sucesivos ciclos de 'tostado y reacción' de manera continua. No obstante, las pruebas realizadas pusieron en evidencia que el conocimiento técnico del metalurgo es el elemento más importante de estos procesos. En efecto, si el primer ciclo fue relativamente simple de dominar, los posteriores ciclos, llevados a término en una estructura que se mantuvo constantemente caliente, fueron más delicados. Sobre todo, mantener la cámara de reverberación a una temperatura baja con el propósito de permitir la desulfuración de la galena, sin fundirla. La producción de una mata (sulfuro de plomo líquido) en esta fase es algo que se debe evitar porque involucra a toda la carga, y el proceso no puede reanudarse una vez que se acumula la carga contra la puerta. De ser así, es necesario extraerla 
y enfriarla para luego reintroducirla en el horno. El rendimiento obtenido en las pruebas realizadas fue alrededor del 30\% del plomo disponible en el mineral. El resto del metal se perdió en el humo y en las reacciones con el suelo del horno, activando la formación de escoria. De manera significativa, el compuesto del slagglass experimental comparado fue bastante similar (alrededor del $70 \%$ de $\mathrm{Pb}$ ) a los arqueológicos hallados en Vila Punku Cueva, aunque no equivalente dado que el mineral procesado no fue el mismo que el utilizado por los antiguos metalúrgicos de Santa Isabel. Por otra parte, las pruebas realizadas permitieron caracterizar la función de las distintas aberturas. Las tres ventanas en la parte superior de la solera sirvieron tanto para las recargas de mineral como para reducir la temperatura y favorecer una atmósfera oxidante. Finalmente, la abertura superior resultó de utilidad durante las fases "frías" de reparación y recarga.

\section{Fase experimental 2}

La segunda aproximación experimental tuvo dos objetivos principales. Por un lado comprobar la factibilidad de llevar a cabo operaciones metalúrgicas en un modelo de horno de reverbero considerablemente más pequeño que el anterior. Por otro lado, se procuró comprender aspectos técnicos de su construcción, intentando en ello reproducir los registros obtenidos, particularmente los restos de argamasa con impronta de textiles, tanto en instalaciones prehispánicas como coloniales. Tomando como base los registros realizados en el Sector 1 de Pulac050 y en las instalaciones coloniales de Santa Isabel y San Antonio, se construyó un modelo experimental compuesto de tres cuerpos: una cámara de fuego, una cámara de trabajo y una chimenea. El horno fue construido con piedras y argamasa, de una longitud de $1.2 \mathrm{~m}$, un ancho máximo de $0,65 \mathrm{~m}$ en la cámara de trabajo y una altura máxima (chimena) de $1 \mathrm{~m}$. El horno fue construido y puesto en fucionamiento en el predio de Pucará de Tilcara, sobre los $2700 \mathrm{msnm}$. Antes de comenzar la construcción del horno, informaciones obtenidas en la población local nos permitieron plantear una hipótesis sobre la manera de elaborar las bóvedas, derruidas en los hornos arqueológicos, así como también sobre la formación de elementos estructurales de argamasa comportando improntas irregulares de textiles que fueron halladas en las instalaciones arqueológicas (Figura 11). Los pobladores locales consultados nos explicaron, en efecto, cómo ellos construyen, durante sus estancia en los valles, un modelo de horno de pan de uso temporario. La bóveda de estos hornos, la parte más complicada de la construcción, es realizada mediante un molde positivo de estiércol y ramas, sobre el cual aplican luego una capa de argamasa. Partiendo de estas informaciones, se procedió a construir en el modelo experimental las bóvedas de las cámaras de fuego y de trabajo utilizando una estructura de paja y ramas, sobre la cual se colocó primero una capa de textil rústico, y luego varias capas de argamasa hasta alcanzar un espesor semejante a los fragmentos hallados en contextos arqueológios (aproximadamente 2,5 cm). El mineral procesado fue igualmente galena, utilizando como combustible únicamente leñas locales. Para monitorear la temperatura se colocaron dos termocuplas, una en la cámara de trabajo y otra en la chimena. Asimismo, durante las operaciones se monitoreó la velocidad del viento en la cámara de fuego. Una vez concluida y secada la estructura, se procedió a encender la cámara de fuego con leña, en un principio avivando el fuego constantemente. A los 15 minutos el horno alcanzó los $300{ }^{\circ} \mathrm{C}$, y al cabo de 1,45 horas, los $800{ }^{\circ} \mathrm{C}$ con un aporte de viento de $2,6 \mathrm{~m}-2,8 \mathrm{~m} / \mathrm{s}$. De manera significativa, se constató que cuando se tapaba la cámara de fuego la temperatura descendía rapidamente. Una vez alcanzada una temperatura adecuada, se introdujeron en la cámara de trabajo 5 $\mathrm{kg}$ de mineral molido. Como en la prueba anterior, pocos minutos después el horno entró en una fase de tostado del mineral, emanando por la chimenea abundante humo blanco. Si bien, a diferencia de la anterior aproximación experimental, solo se lograron resultados parciales (mata), la temperatura del horno experimental osciló entre los $950^{\circ} \mathrm{C}$ y 1000 ${ }^{\circ} \mathrm{C}$, logrando por momentos superar los $1200{ }^{\circ} \mathrm{C}$ con un viento de 5-6 m/s. En este sentido, las temperaturas alcanzadas confirman la viabilidad de este modelo reducido. No obstante, el resultado más significativo fue el haber reproducido, tanto en la cámara de alimentación como en la cámara de trabajo y la chimenea, elementos estructurales análogos a los observados en los sitios arqueológicos prehispánicos y coloniales, siendo los segmentos de argamasa con impronta de textil utilizados en las bóvedas muy semejantes a los hallados en Pulac050 y en las 


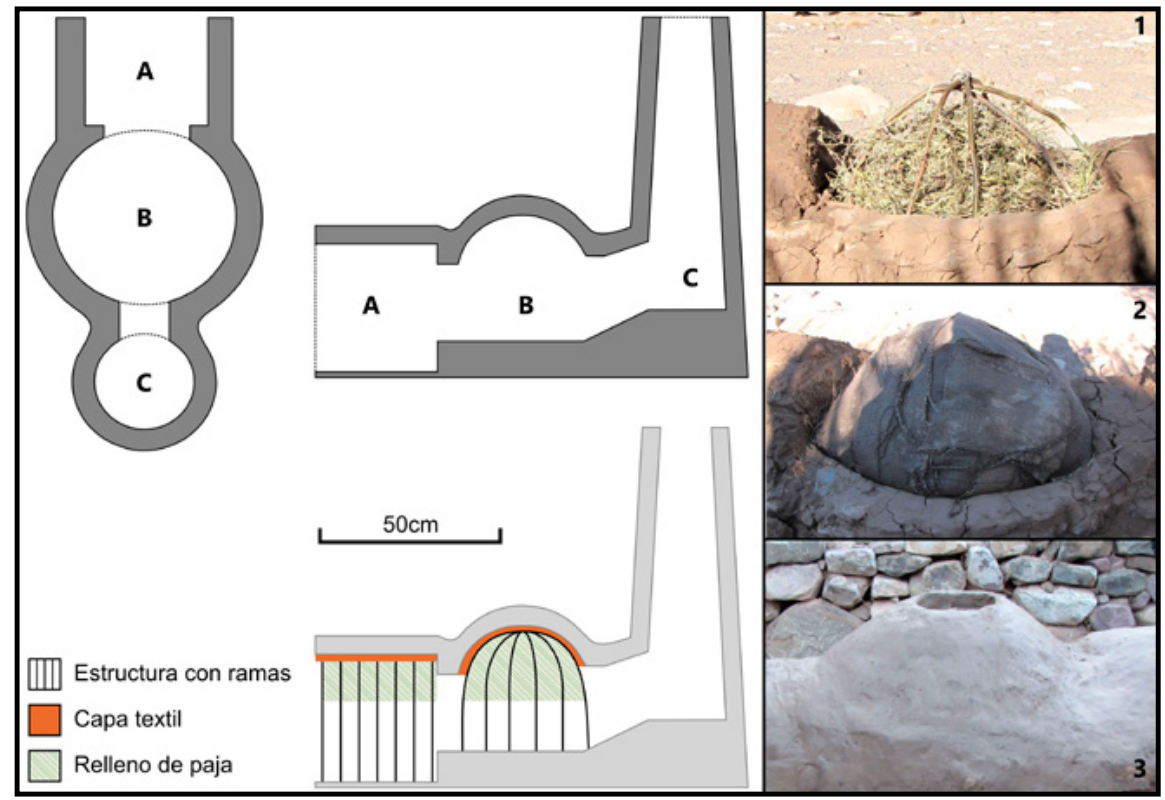

Figura 11. Croquis del horno de reverbero experimental elaborado en Tilcara y fotografías del proceso de construcción de la bóveda utilizando estructura de ramas y paja, capas de textiles rústicos y argamasa.

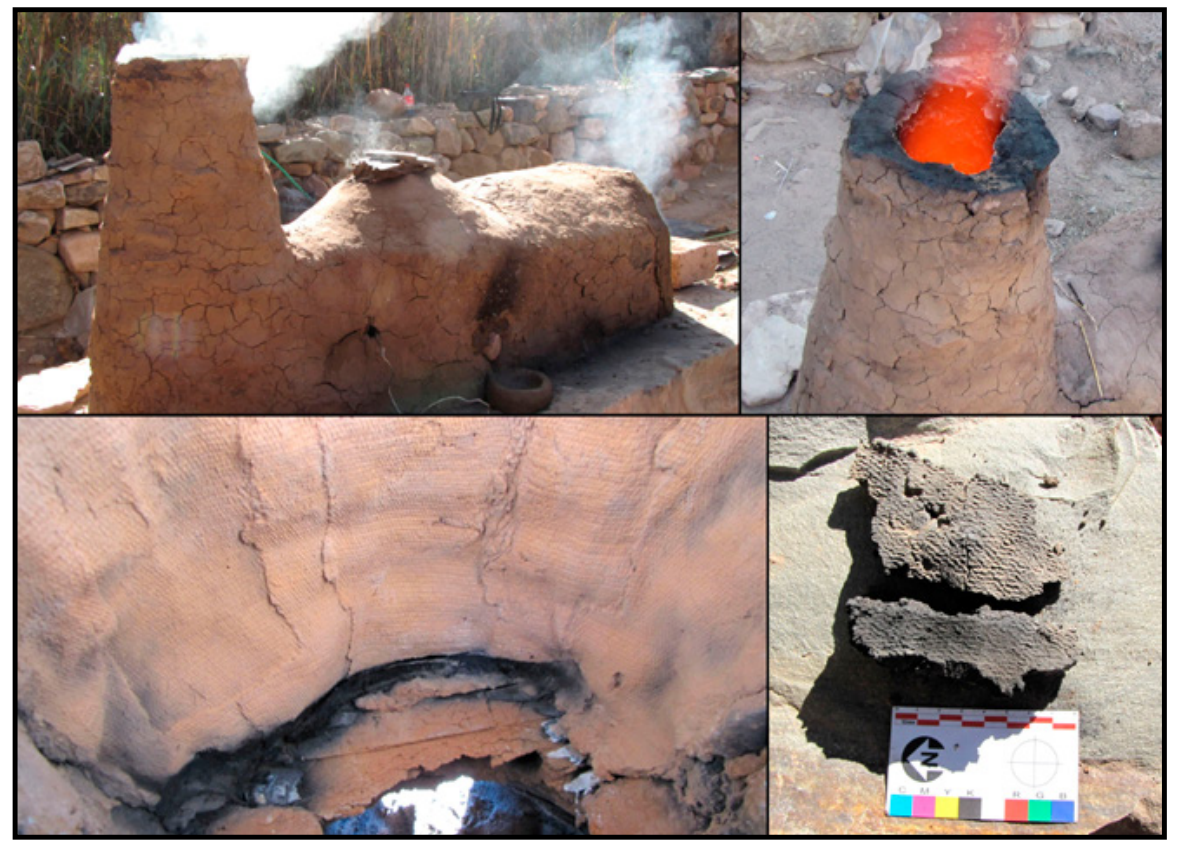

Figura 12. Fotografías del horno experimental de Tilcara. Arriba izquierda: el horno en fase de gasificación (tostado). Arriba derecha: detalle de la chimenea durante la fase de mayor temperatura alcanzada. Abajo izquierda: interior de la bóveda de la cámara de fuego exponiendo una impronta textil irregular. Nótese la semejanza con los fragmentos arqueológicos en Figura 9.

Abajo derecha: fragmentos con impronta textil desprendidos de la bóveda de la cámara de trabajo. 
instalaciones coloniales (Figura 12). Comprender la formación de estos materiales fue una etapa clave para confirmar la existencia de continuidades tecnológicas en esta categoría de horno entre las épocas prehispánicas y colonial.

\section{¿Una tecnología andina adoptada en Europa?}

Las referencias sobre hornos de reverbero metalúrgicos más antiguas en Europa aparecen en los famosos tratados de Biringuccio (1990 [1540]) y Agricola (1986 [1556]). Sin embargo, estas referencias -de igual modo poco precisas-, muestran en su mayoría modelos que son sustancialmente diferentes a los andinos, ya sea por funcionar exclusivamente con ventilación por fuelles, o por no contar con una cámara de fuego ubicada por delante de la cámara de trabajo, con una chimenea por detrás de la misma, o bien, ninguno de estos cuerpos (Figura 13). Por otra parte, las primeras referencias sobre esta tecnología metalúrgica, en su aserción moderna, es decir, con una cámara de combustible y chimenea separadas de la cámara de trabajo, aparecen recién en Inglaterra en 1678 (Tylecote, 1992) y se desarrollan en Alemania solo a comienzos del siglo XVIII, y en la segunda mitad del siglo XVIII en Francia (Schlutter, 1753; Brûlé, 1994). En concordancia con estas fuentes, el único ejemplo arqueológico a la fecha conocido de este modelo de horno fue hallado en el sitio de Pampailly, en Francia, el mismo adscrito a finales del siglo XVIII (Benoit, 1997, Ch. 8). En cambio, hemos visto que primeras referencias documentales en los Andes sobre esta categoría de horno, acompañadas de descripciones precisas sobre su forma $y$ modo de funcionamiento, aparecen ya en 1618 en Oruro (Cobo (1890[1653]) y alrededor de 1626 en los Lípez (Barba, 1770 [1640]). Como fue señalado antes, ambas referencias muestran ya un lenguaje técnico bien definido, por lo que se puede deducir que tal tecnología se remontaría por lo menos a las últimas décadas del siglo XVI y primeras del XVII. Recordemos también que para Barba (1770 [1640], p. 138) el modelo andino representaba una novedad, en tanto que para Montesinos (1638, pp. 278-279) resultarían de una invención local. En este sentido, cobran relevancia aquí las referencias y descripción de los tocochimbos indígenas señalados por el padre Barba, así como también los hornos registrados tanto en Pulac050 (Cruz, 2010; Lechtman et al., 2011) y otros establecimientos prehispánicos, como Curamba (Parodi et al., 2008), que demuestran el conocimiento de esta tecnología en tiempos prehispánicos. Más aún, hemos observado algunas continuidades tecnológicas entre las estructuras y materiales hallados en el sitio prehispánico de $\mathrm{Pu}$ lac050 y aquellos registros efectuados en instalaciones metalúrgicas como Escoriani, Santa Isabel y San Antonio. En todo caso, sabemos por las fuentes y los testimonios arqueológicos que su empleo se habría generalizado por todas las áreas mineras surandinas desde las décadas finales del siglo XVI, muy probablemente acompañando los consecutivos "descubrimientos" de nuevas minas tras la caída del mineral de Potosí.

Por su parte, las informaciones que podrían referir al ingreso de esta tecnología en Europa aparecen en España recién a partir de 1630 , en cédulas reales otorgando privilegios a "descubridores" de nuevos métodos de fundición. Entre ellos se resaltan los nombres de algunos personajes que nos son conocidos por haber participado muy activamente en las dinámicas de desarrollo e innovación tecnológica que tuvo lugar en los Andes, particularmente en Potosí, desde el último cuarto del siglo XVI, como Carlos Corzo, el cura Lorenzo de Mendoza, Pablo de Rivadeneira, Francisco Moreno, y el propio Álvaro Alonso Barba. El retorno de estos especialistas españoles no fue algo fortuito, sino que respondió al interés de la Corona en incrementar la producción minera en la península. En efecto, en 1584 se dictó una ordenanza para convocar a especialistas, ya fueran europeos o españoles radicados en el Nuevo Mundo, para el beneficio de las minas españolas, ${ }^{17}$ nombrando por la misma en 1594 a Carlos Xedler (Karl Schedler) como Administrador General de Minas del Reino. Así, en 1609, Carlos Corzo, quien junto a su hermano inventaron en Potosí un nuevo método de beneficio con azogue agregando limaduras de hierro, llega a España, otorgándosele inmediatamente el título de Alcalde Mayor de Minas (Sánchez Gómez

17 “Título de administrador general de minas del reino á don Cárlos Xedler para desde 31 de diciembre de mil quinientos noventa y cuatro en adelante" (González, 1832, pp. 23-29). 


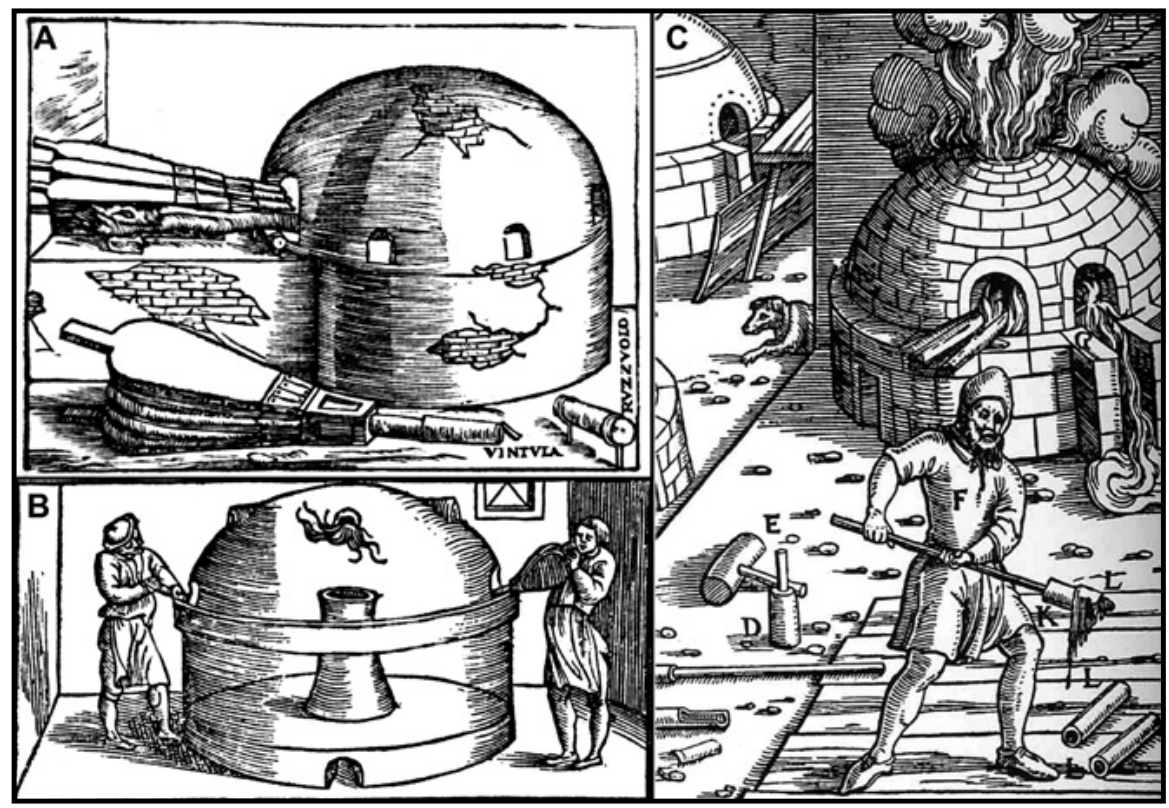

Figura 13. Grabados que exponen modelos de horno de reverbero utilizados en Europa.

A. Biringuccio (1540: 130); B. Biringuccio (1540: 118); C. Agricola (1556:384).

et al., 1997, p. 191). En 1630 se le otorga el título de "ensayador y beneficiador general de las minas de Plata por azogue" a Martín de Soto, "minero y beneficiador de las minas del Perú” (González, 1835, pp. 122-124). Ese mismo año se le otorga una cédula a Gonzalo Romero, llegado del Perú, para utilizar "ingenio de fuelles" para fundir minerales (González, 1835, pp. 128-136) y otra al cura Lorenzo de Mendoza, quien, significativamente, pasó largos años en las minas altoandinas de Chichas, ${ }^{18}$ para administrar las minas de oro de Plasencia (González, 1835, pp. 136-138). Siguiendo esta nómina, en 1632 se le otorga una Cédula a Antonio de Mesones para "ensayo y beneficio general de las minas" (González, 1835, pp. 158-160) y en 1633 un Privilegio a Pablo Antonio de Rivadeneira, "descubridor" de las minas de Caylloma para usar un modelo de "horno sin fuelles" utilizando una caja de agua que produce viento (González, 1835, pp. 160-163). En 1635

18 Al respecto, como lo seńala Ramada Curto (2010, p. 29), el padre Lorenzo de Mendoza estuvo directamente involucrado en la organización de las principales minas de Chichas: Tatasi, Chorolque, San Vicente, Monserrate, Chocaya y Sorocaya. La experiencia adquirida en estas minas le valieron una reputación que trascendió los Andes. se concede una Cédula Real a Francisco Ibáñez de Marquina (González, 1835, pp. 163-164) por haber "descubierto" un nuevo beneficio del mineral de plata en horno de reverbero "nunca implementado en España ni en las Indias", utilizando, curiosamente, baño de plomo (soroche). ${ }^{19}$ Más explícitamente, en febrero de 1644, se otorga otro Privilegio a Francisco Moreno (González, 1835, pp. 174-177), quien venía de Potosí, por la invención de "un ingenio y horno de fuego, de cuyo modelo hacia presentación, en el cual sin costa de azogues, de fuelles, ni de carbón, solamente con leña, con facilidad indecible se funden todo género de metales [...] cosa hasta hoy ni de antiguos ni de modernos egecutada". Es importante tener en cuenta aquí que estas "invenciones", al igual que los "descubrimientos" de minas, fue una generalizada fórmula administrativa, cercana a la actual noción de patentamiento, utilizada

19 "Se me ha hecho relación que habeis gastado mucha parte de vuestra hacienda en inquirir el verdadero y mayor beneficio de las minas de oro y plata, de que hicísteis prueba dello en la mina de plata de la villa de Calcena por fundición y baño de plomo por horno de reverbero, beneficio que es nuevo, y que nunca se ha usado dél en estos reinos, ni en los de las Indias, y para beneficiar el metal negrillo y los demás” (González, 1832, p. 163). 
tanto para reconocer oficialmente aquellos inventos novedosos, valga la redundancia, como para aquellas tecnologías ya existentes pero desconocidas en el reino. Finalmente, en 1658 el mismo Álvaro Alonso Barba regresa a Espańa para trabajar el mineral de Río Tinto. Lo acompañan el experto metalurgo Agustín Núñez de Zamora y Juan de Figueroa, minero y beneficiador de las minas de Caylloma (Sánchez Gómez et al., 1997, p. 193). Entre sus experiencias en la península destaca el procesamiento de escoriales de mineral de plata de la época romana, fundiendo las escorias en hornos con la ayuda de 'soroche' (galena argentífera) como fundente, un procedimiento que el cura minero aprendió, sin duda alguna, de los metalurgos surandinos (Sánchez Gómez et al., 1997, p. 195). Los casos citados, que forman parte de una nómina más extensa, ilustran el gran interés que tuvo la Corona en aplicar en los minerales de la península aquellas tecnologías y saberes metalúrgicos del "Nuevo Mundo", replicando en ello la dinámica de invenciones y transferencias que comenzó a desarrollarse en torno a los centros mineros andinos algunas décadas antes (Salazar Soler, 2009; Bigelow, 2012). Es muy probable que el modelo de horno presentado por Francisco Moreno o los hornos utilizados por Barba para procesar el mineral de Río Tinto no hayan tenido como modelo sus pares andinos.

\section{Consideraciones finales}

Los hornos de reverbero tratados aquí muestran diferentes modelos que relevan de una misma categoría, mostrando algunas continuidades muy significativas con la tecnología metalúrgica desarrollada en tiempos prehispánicos. Al mismo tiempo, ellos reflejan dinámicas tanto de transferencia de saberes como de adaptación e innovación tecnológica, que si bien estuvieron, en todos los casos, vinculadas con el mundo indígena, pudieron incluir conocimientos y experiencias europeos. En este sentido, nos muestran otro aspecto, menos conocido y poco referido en las fuentes documentales, de las intensas dinámicas de desarrollo e innovación en la metalurgia que tuvo lugar en los Andes desde finales del siglo XVI. En todo caso, sabemos por los testimonios materiales hallados que su empleo se habría generalizado por todas las áreas mineras surandinas durante las décadas finales del siglo XVI y primeras del XVII, tras los consecutivos "descubrimientos" de nuevas minas motivados por la caída del mineral de Potosí, como también por la imperiosa necesidad de reducir -o evitar- el consumo de azogue. Ciertamente, el uso generalizado de estos hornos, sobre todo aquellos localizados en parajes poco visibles y alejados de los centros mineros, como los de Vila Punku Cueva, Santa Isabel y Ecoriani, tuvo que ver también con la enorme producción de plata clandestina o "sin quintar” que existió a todo lo largo del período colonial.

Hasta hace poco tiempo, sobresalían en la historiografía andinista las wayras, los afamados hornos de viento, consideradas como ejemplo emblemático -en ocasiones como el único ejemplo- de una metalurgia indígena medianamente sofisticada. Sin duda esto tuvo que ver tanto con la importancia capital que tuvieron las wayras durante los primeros años del mineral de Potosí como con la fascinación que estos rudimentarios pero muy eficaces dispositivos provocaron en los espańoles. Esta relevancia se mantuvo vigente todavía varios siglos después que dejaron de ser utilizadas y quedó plasmada en un importante corpus de referencias y descripciones en las fuentes documentales de la época y que se encuentran disponibles. En contraste, las informaciones sobre los antiguos hornos de reverbero andinos que tratamos aquí son más escasas, y salvo contados casos, bastantes ambiguas. Tampoco en la historiografía andinista se refleja mucho interés por este tipo de horno, considerado a priori como de origen europeo. Aparte de su aparición tardía en las fuentes, al menos otros dos componentes intervinieron en formar esta caracterización historiográfica. Por un lado, replicando un discurso colonial muy generalizado en el ámbito de la minería y el beneficio de los metales, la idea de que, en contraste con una metalurgia prehispánica limitada y de baja escala, todas las "innovaciones" tecnológicas post conquista vinieron por el lado de los europeos. Por el otro, la semejanza entre este modelo andino y ciertos modelos europeos, la que, al final de cuentas, se resume a la cámara de trabajo con cubierta abovedada. Ambos argumentos pueden hoy ser discutidos. Por un parte, numerosas investigaciones arqueológicas nos cambian hoy el panorama de la producción de metales en tiempos prehispánicos, poniendo en evidencia una metalurgia indígena 
tecnológicamente más diversificada y sofisticada. ${ }^{20}$ No se trata ya solo de wayras, tocochimbos y rústicos dispositivos, sino de un amplio y variado repertorio de hornos y estructuras de combustión, que se ajustaron a las diferentes naturalezas de los minerales, a las rudas condiciones ambientales y a la escasez de recursos disponibles (combustible, agua, etc.). Por otra parte, como hemos visto en el caso del horno H1 del sitio Pulac050, el concepto del horno de reverbero era conocido y dominado por los metalurgos andinos por lo menos varios siglos antes de la llegada de los españoles. De hecho, también fue aplicado para la producción alfarera, tal el caso de los hornos de La Troya (Feely, 2010). Y es que estos hornos se rigen por un principio muy sencillo: reflejar el calor en una cámara separada de la fuente de fuego, la cual, siguiendo el comportamiento ondulante de las propias llamas, posee una cubierta abovedada. En cambio, dominar la naturaleza de los elementos, los tiempos, las temperaturas y las atmósferas, requiere una acumulación de saberes muy especializados, una experticia formada tras siglos de experimentaciones. El horno de reverbero de tres cuerpos es un resultado de esta competencia; su eficiencia se reflejó en las pruebas experimentales tanto en la simpleza de su construcción como en la capacidad para alcanzar altas temperaturas solo con una ventilación natural y en el consumo reducido de combustible.

Contrariamente, hemos visto que la difusión en Europa de esta categoría de horno de reverbero, compuesto por tres cuerpos diferenciados, es posterior a las descripciones de Cobo, Barba y Capoche. Y de hecho, las primeras informaciones alusivas a esta tecnología aparecen en España recién a partir de los años 1630, en Cédulas y Privilegios otorgados a "descubridores" de nuevos métodos de fundición, quienes en su mayoría eran españoles que retornaron a la península tras una larga experiencia en las minas y centros metalúrgicos andinos. Muchos de ellos, como Carlos Corzo, Lorenzo de Mendoza, Francisco Moreno y el propio Álvaro Alonso Barba, no solo fueron avezados expecialistas en el beneficio

20 Entre otros, González (2004), Van Buren y Mills (2005), Vetter Parodi et al. (2008), Angiorama y Becerra (2010), Becerra et al. (2014), Salazar et al. (2013), Mille et al. (2013), Cruz (2010), Lechtman et al. (2011), Spina y Giovannetti (2014), Téreygeol y Cruz (2014). de los minerales, sino que también poseían amplios conocimientos sobre las tecnologías utilizadas por los indígenas surandinos. De esta manera, en la intensa dinámica de transferencia de saberes e innovación tecnológica, iniciada en los centros mineros andinos y después replicada en España, fue que los hornos de reverbero andinos, o algunos de sus principios tecnológicos, cruzaron el océano para luego difundirse progresivamente sobre una gran parte de Europa.

\section{Agradecimientos}

Nuestros agradecimientos a Daniel Vera de la carrera de Arqueología de la UMSA por su participación, en el marco de su tesis de licenciatura, en la elaboración y pruebas experimentales realizadas en Tilcara. Este estudio fue financiado por el proyecto MINCyT-ECOS No. A08H05 "Gestión de recursos y producción de metales en el Altiplano surandino entre los siglos X y XVIII, y fondos de investigación del CONICET y del CNRS LAPA-IRAMAT.

\section{Referencias citadas}

Agricola, G. (1986 [1556]). De re metallica. Bâle: H. C. Hoover \& L. H. Hoover.

Angiorama, C. y Becerra, M. F. (2010). Evidencias antiguas de minería y metalurgia en Pozuelos, Santo Domingo y Coyahuayma (Puna de Jujuy, Argentina). Boletin del Museo Chileno de Arte Precolombino, 15(1), 81-104.

Barba, Á. (1770 [1640]). Arte de los metales. Madrid: Imprenta del Reyno. Copia digital. En Biblioteca El Dorado, Sucre. Archivo y Bibliotecas Nacionales de Bolivia.

Becerra, M. F., Nieva, N. y Angiorama, C. (2014). Caracterización de desechos de fundición arqueológicos: la metalurgia colonial en Fundiciones 2, Rinconada. Jujuy. Revista de ciencia y tecnología, 21, 58-64. Buenos Aires

Benoit, P. (1997). La mine de Pampailly, XVe-XVIIIe siècles. Chapitre 8. La métallurgie du plomb : la Révolution de la houille. Lyon: Alpara

Bigelow, A. (2012). La técnica de la colaboración: redes científicas e intercambios culturales de la minería y 
metalurgía colonial altoperuana. Anuario de estudios bolivianos, archivisticos y bibliográficos, 18, 53-77. Sucre. Archivo y Bibliotecas Nacionales de Bolivia.

Biringuccio, V. (1990 [1540]). De la Pirotechnia. Nueva York: Dover Publications.

Brûlé, A. (1994). L'introduction en France du four à réverbère: l'apport de l'analyse historique. En Benoit P. (Dir.). Mines et métallurgie, Les chemins de la recherche, 21, 285298. Lyon. Programme Pluriannuel en Sciences Humaines Rhône-Alpes.

Cabrera, G. de (1571). Orden que se dio en Potosi para que los indios no hiciesen fundiciones de plata y nombramientos de alcaldes que se hicieron en varias doctrinas. BN3040, fs. 167r-169v. Madrid: Biblioteca Nacional de España.

Capoche, L. (1959 [1585]). Relación general de la Villa Imperial de Potosí. Madrid: Biblioteca de Autores Españoles.

Cobo, B. (1890[1653]). Historia del Nuevo Mundo, T. I. Sociedad de Bibliófilos Andaluces. Sevilla: Imprenta de E. Rasco.

Cruz, P. (2010). Tumbas, metalurgia y complejidad social en un páramo del altiplano surandino. Pulacayo, Bolivia, $\mathrm{I}^{\mathrm{er}}$ milenio d. C. Revista Andina, 49, 71-103. Cuzco. Centro Bartolomé de Las Casas.

Cruz, P. y Téreygeol, F. (2014). Yanaconas del rayo. Reflexiones en torno a la producción de metales en el espacio surandino (Bolivia, siglos XV-XVI). Estudios Atacameños. Arqueologia y Antropología Surandinas, 49, 19-44.

Cruz, P. y Téreygeol, F. (2016). El mineral rebelde. El lado indígena de la producción de plata durante los primeros momentos de la Colonia (Bolivia, siglos XVI-XVII). Revista de Arqueología Histórica Argentina y Latinoamericana, 10(2), 31-56. Sociedad Argentina de Antropología, Buenos Aires.

Cruz, P., Nielsen, A., Téreygeol, F., Deroin, J.-P. y Guillot, I. (2011). La pacificación del mineral. Cerro Lípez, un enclave minero en la contienda sobre el Nuevo Mundo. Vestigios-Revista Latinoamericana de Arqueología Histórica, Número especial Arqueología de la minería, 11-44. Minas Gerais. Fac. de Filosofia e Ciências Humanas, UMFG.
Del Benino N. (1965[1573]). Relación muy particular del Cerro y minas de Potosí y de su calidad y labores. En Jiménez de la Espada (Comp.). Relaciones Geográficas de Indias. Tomo II (pp. 362-371). Madrid: Biblioteca de Autores Espańoles.

Feely, A. (2011). Caracterización de estructuras de doble cámara para la cocción de artefactos cerámicos en La Troya (Tinogasta, Catamarca). Relaciones, XXXVI, 325-330.

Garcilaso de la Vega, I. (1985 [1609]). Comentarios reales de los Incas. Caracas: Fundación Biblioteca Ayacucho.

González, L. (2004). Bronces sin nombre. La metalurgia prehispánica en el Noroeste Argentino. Buenos Aires: Ediciones Fundación CEPPA.

González, T. (1832). Registro y relación general de minas de la Corona de Castilla. Tomo II. Madrid: Imprenta de Don Miguel de Burgos.

Lechtman, H., Cruz, P., Macfarlane, A. y Carter, S. (2011). Procesamiento de Metales durante el Horizonte Medio en el Altiplano Surandino (Escara, Pulacayo, Potosí). Boletin del Museo Chileno de Arte Precolombino, 15(2), 9-27. Santiago.

Mille, B., Salazar, D., Bourgarit, D., Figueroa, V., Perlès, C. y Berenguer, J. (2013). Emergence of large scale copper production during the Early Bronze Age in Saint-Véran (France) and in Prehispanic Northern Chile: a comparative research program. The Crucible, 84, 8-9. Londres. The Historical Metallurgy Society.

Montesinos, F. de (1832[1638]). Directorio de Beneficiadores, con reglas ciertas para los negrillos. Registro y Relación general de Minas de la Corona de Castilla, II y III parte. Madrid: Miguel de Burgos.

Parodi, L., Petrick Casagrande, S., Huaypar Vásquez, Y., Mac Kay Fulle, M. (2008). Los hornos metalúrgicos del sitio Inca de Curamba (Perú): estudio por DRX, espectroscopia Mossbauer y datación por métodos de luminiscencia. Bulletin de l'Institut Français d'Études Andines, 37(3), 451-475. Lima.

Pfordte, O. F. (1893). Ancient Method of Silver-Lead Smelting in Peru. Transactions of the American Institute of Mining Engineers, 21, 25-30. 
Ramada Curto, D. (2010). O Padre Lourenço de Mendonça: entre o Brasil e o Peru (c. 1630 - c. 1640). Topoi, V11, 20, 27-35.

Rivera Casanovas, C. (2008). Aproximación inicial a la explotación minera y metalurgia prehispánica en la región de San Lucas, Chuquisaca. En Cruz, P. y Vacher, J.-J. (Eds.). Minas y Metalúrgias en los Andes del Sur, entre la época prehispánica y el siglo XVII, (pp. 139-162). Sucre: IFEA - IRD.

Salazar Soler, C. (2009). Los expertos de la Corona. Poder colonial y saber local en el Alto Perú de los siglos XVI y XVII. De Re Metallica, 13, 83-94. Madrid: Sociedad Española para la Defensa del Patrimonio Geológico y Minero.

Salazar, D., Berenguer, J. y Vega, G. (2013). Paisajes minero-metalúrgicos Inkaicos en Atacama y el altiplano sur de Tarapacá (norte de Chile). Chungara. Revista de Antropología Chilena, 45(1), 83-103.

Sánchez Gómez, J., Mira Delli-Zotti, G. y Dobado, R. (1997). La savia del Imperio. Tres estudios de economía colonial. Acta Salmanticensia. Salamanca: Ediciones Universidad de Salamanca.

Schlutter, C. (1753). De la fonte des mines, des fonderies etc. París: Hellot

Spina, J., Giovannetti, M. y Ferraris, E. (2017). Interrogantes de la metalurgia prehispánica andina. Nuevas propuestas desde los hornos de Quillay (Catamarca, Argentina). Chungara. Revista de Antropología Chilena 49(3), 327-342. [online]

Spina, J. y Giovannetti, M. (2014). Metalurgia prehispánica en el valle de Hualfín: Nuevos datos sobre Quillay. Intersecciones en Antropología, 15(2), 473-477.
Téreygeol, F. y P. Cruz. (2014). Metal del viento. Aproximación experimental para la comprensión del funcionamiento de las wayras andinas. Estudios Atacameños. Arqueología y Antropología Surandinas, 48, 39-54.

Téreygeol F., Cruz, P., Guillot, I. y Méaudre, J. C. (2016). Silver ores smelting process in reverberatory furnace (Santa Isabel mine, XVII c., Dept. Potosí, Bolivia): Experimental approach of South-American inventions. En Alonso, R., Canales, D. y Baena, J. (Eds.). Playing with the time. Experimental archeology and the study of the past. Madrid: Servicio de Publicaciones de la Universidad Autónoma de Madrid.

Van Buren, M. y Cohen, C. (2010). Technological changes in silver production after the spanish conquest in Porco, Bolivia. Boletín del Museo Chileno de Arte Precolombino, 15(2), 29-46.

Van Buren, M. y Mills, B. (2005). Huayrachinas and tocochimbos: traditional smelting technology of the southern Andes. Latin American Antiquity, 16(1), 3-25.

Vetter Parodi, L., Petrick Casagrande, S., Huaypar Vásquez, Y. y Mackay Fulle, M. (2008). Los hornos metalúrgicos del sitio Inka de Curamba (Perú): estudio por DRX, espectroscopia Mössbauer y datación por métodos de luminiscencia. Bulletin de l'IFEA, 37(3), 451-475.

Weaver, B. (2008). Ferro Ingenio: An Archaeological and Ethnoarchaeological View of Labor and Empire in Colonial in Porco and Potosí. Tesis de Maestría. Kalamazoo. Western Michigan University. www.brendanweaver.net/anthro/ Weaver_MA_Thesis_2008.pdf 